\title{
A Novel Systematic Methodology for Ship Propulsion Engines Energy Management
}

\author{
Konstantinos Tsitsilonis and Gerasimos Theotokatos*
}

Maritime Safety Research Centre, Department of Naval Architecture, Ocean and Marine Engineering, University of Strathclyde, 100 Montrose Street, Glasgow, G4 0LZ, Scotland, UK

* Corresponding author.

1 The authors contributed equally to this work.

\begin{abstract}
Establishing an energy monitoring and management methodology is a quintessential milestone for informed energy savings decision making as well as for effectively reducing the cost and the environmental impact of shipping operations. In this study, a novel systematic methodology is proposed for the energy management of the ship propulsion engine, which is the largest ship energy producer. The methodology employs a combination of tools including statistical analysis, predicting the engine air flow via compressor modelling and energy and exergy analyses, whereas its output includes the engine operating profile, the most frequently occurring propeller curves and the engine most frequent operating points, the key performance indicators for quantitatively assessing the recorded parameters quality as well as the energy and exergy flows and exergy destruction of the engine components. The methodology is implemented for three case studies for a very large crude carrier, a container ship and a bulk carrier, for which recorded data were available by using different monitoring techniques from either noon reports of automatic data acquisition systems. The derived results provide the engine operating profile demonstrating that the investigated vessels were operating in slow steaming conditions with a lower engine efficiency associated with a greater exhaust gas wasted energy. The measured data analysis demonstrates the better quality of the data recorded by automated monitoring systems and pinpoint maintenance issues of the engine components. Lastly, the exergy analysis results demonstrate that the exhaust gas and jacket cooling water provide the greater exergy flows rendering them attractive for energy saving initiatives, whereas the engine block, compressor and turbine are the engine components with the greater exergy destruction, thus requiring closing monitoring for timely identifying mitigating measures.
\end{abstract}

Keywords: Systematic methodology, Energy Management, Ship propulsion engine, statistical analysis, quantification of measurements quality, energy and exergy analyses

\section{Highlights}

- A systematic methodology for ship engines energy management was developed

- Employs statistical analysis, compressor modelling and energy/exergy analyses

- Engine operating profile is identified and measured parameters quality is quantified

- Automatically recorded data exhibits better quality versus noon reports data

- Deviations in the actual engine operation from baseline conditions were identified

- Energy saving initiatives are proposed based on the developed methodology results 


\section{INTRODUCTION}

Due to their large efficiency, marine diesel engines represented $65 \%$ of the marine propulsion market in 2016, with a 4.3\% growth forecast by 2024 (GMI, 2017). However, international shipping, although it is the most efficient mode of transportation, is still responsible for over 10\% of anthropogenic NOx and SOx emissions as well as $3 \%$ of $\mathrm{CO}_{2}$ emissions (IMO, 2015). Within that context, considerable efforts have been dedicated by both international and national regulatory authorities in setting stringent efficiency standards for ships as well as implementing energy and emissions monitoring. For controlling the $\mathrm{CO}_{2}$ emissions from ships, the International Maritime Organisation (IMO) introduced the energy efficiency design index (EEDI) regulation along with the energy efficiency operational indicator (EEOI) and the Ship Energy Efficiency Management Plan (SEEMP) regulations, whereas EU introduced legislation for the $\mathrm{CO}_{2}$ emissions monitoring reporting and verification (MRV) (EC, 2013; IMO, 2014; IMO, 2012; Blanco-Davis \& Zhou, 2016). As the emissions reduction is directly related to the fuel consumption and the fuel cost is one of the most significant contributors to the ship operational expenditure (OPEX), fuel saving initiatives have become requisite (Abadie, et al., 2017; Adland, et al., 2018; Brynolf, et al., 2014; Deniz \& Zincir, 2016).

Due to its influence on both the economic and environmental indicators, the ship energy efficiency has been a subject attracting the interest of the academia as well as the maritime industry stakeholders (Johnson, et al., 2013; Chi, et al., 2018; Lützen, et al., 2017; Wang, et al., 2016; Jensen, et al., 2018; Baldi, et al., 2016). Previous studies proposed new technologies, policies and measures as well as investigated approaches and benchmarking practices for the vessel efficiency improvement (Cichowicz, et al., 2015; Blanco-Davis \& Zhou, 2016; Jeong, et al., 2018). In addition, methodologies for studying the exergy and energy flows of the ship energy systems have been proposed (Baldi, et al., 2015; Dimopoulos \& Kakalis, 2014) mostly focusing on the main engine as the major ship energy producer. However, realistic operating profiles for the ship navigation and engine performance parameters corresponding to the ship life cycle are required for implementing these approaches. Furthermore, the multiple operating points of the engine operating profile have not been examined separately as the estimated energy flows are usually aggregated over the entire engine operating envelope. In addition to the above, the ISO 50001 was introduced in 2011 as one of the most prominent energy assessment methodologies (Kanneganti, et al., 2017); however, it is not tailored for marine power plants and its general description of energy management leaves much room for interpretation (Dörr, et al., 2013).

As an outcome of the pertinent literature review, the shipboard measurements and data collection was identified as requisite for the understanding of the ship and her systems performance as well as for pursuing appropriate energy saving initiatives. In this respect, the vessel performance parameters monitoring (Deligiannis, 2017), which entails the measurement of primarily the navigational parameters and the main engine operational parameters (such as draft, weather conditions, speed through water, torque, propeller rotational speed and fuel consumption), has been employed in order to comprehend the trade-offs between the vessel speed, the engine load, and the fuel consumption. Difficulties associated with this approach include the sheer complexity between the ship hull, propeller and machinery interactions (Mizythras, et al., 2018), the considerable inaccuracies of measuring a number of critical parameters (e.g. ship speed and fuel consumption etc.) and the greatly varying environmental conditions, which introduce large uncertainties in the calculated trade-offs and require sophisticated statistical analyses to reject outliers (Aldous, et al., 2015; Galli, et al., 2014; Perera \& Mo, 2017). 
As a more effective approach for the vessel energy systems management, (Dimopoulos \& Kakalis, 2014) proposed the combination of energy and exergy analyses based on collected engine/systems performance parameters (including working media temperatures and pressures, shafts rotational speed and torque, etc.). In this respect, the exergy analysis provides the engine and its components additional parameters including the energy quality and its degradation, the associated performance indicators and the inefficiencies sources, (Dimopoulos \& Kakalis, 2014; Kotas, 1985; Baldi, et al., 2015) . Although the above approaches were used in a number of studies, there is a lack of an approach that can address systematically the ship energy management (Cichowicz, et al., 2015; Meng, et al., 2016).

To support these approaches, different data collection practices employed in the shipping industry for acquiring data on-board ships (Armstrong \& Banks, 2015; Aldous, et al., 2015), in specific: (a) Noon Reports (NR), where the crew is responsible of recording one data entry every 24 hours, and (b) Automatic Data Logging Monitoring (ADLM) systems, which can record a number of parameters at any specified sampling rate that usually results in a vast amount of high-quality data (Nielsen, et al., 2012; Lajic, et al., 2009; Perera \& Mo, 2016). By employing the NR method, the data parameters recorded are limited and the data quality may be doubtable owing to the involvement of the human element. However, despite of the potential advantages of ADLM systems, ship owners/operators have been sceptical with regard to their implementation on-board ships due to the associated costs and the additionally imposed challenges for the crew (Armstrong \& Banks, 2015; Jafarzadeh \& Utne, 2014; Logan, 2011; Poulsen \& Johnson, 2016; Petersen, et al., 2012; Johnson \& Styhre, 2015). Therefore, the largest portion of the world fleet is not equipped with appropriate monitoring equipment (Poulsen \& Johnson, 2016), resulting in a major lack of sufficient quality data, which acts as a barrier in implementing strategies for improving the ship energy efficiency (Jafarzadeh \& Utne, 2014; Rehmatulla \& Smith, 2015).

Due to the lack of high-quality operational data, the wide operating envelope of the propulsion system, the varying environmental conditions and the propulsion system components degradation, as well as the fact that a number of critical parameters cannot be measured with a feasible monitoring system (e.g. air flow), vessel energy systems modelling approaches have been extensively used for well over a decade (Dimopoulos, et al., 2014; Dimopoulos, et al., 2012; Duarte, et al., 2004; Guan, et al., 2014). However, a concept of implementing an integrated approach, which combines (a) measuring data, (b) modelling techniques, and (c) energy/exergy analyses of the system and its components, is emerging as takes advantage of the insight to the system gained by modelling and the more accurate representation of system components provided by the measured data (Baldi, et al., 2015; Dimopoulos \& Kakalis, 2014; Duarte, et al., 2004; Dimopoulos, et al., 2014). However, with the current model-based approaches, inconsistencies and concerns arise regarding the realism and accuracy of the results (Baldi, et al., 2015), as real-time data usage is quite limited, and the energy flows are aggregated over the entire operating envelope. For obtaining a better insight into the state of the system, the integration of an energetic and exergetic analyses with a data-oriented approach, which employs specific operating engine points obtained by analysing a realistic operating profile is requisite. A way to accommodate this is by employing statistical analysis (Perera \& Mo, 2016; Perera \& Mo, 2017) for identifying the main engine Most Frequently Occurring (MFO) operating points and the most frequently occurring propeller curves as an additional metric associated with the ship propulsion plant operational conditions, which has not proposed in previous studies. 
In summary, from the preceding literature review, the following gaps are identified: (a) the lack of a systematic, technically-oriented energy monitoring methodology tailored to the marine industry needs, (b) the need to identify and more accurately represent the actual operating profile of the ship propulsion, (c) the lack of a data-oriented approach for conducting the energy and exergy analyses, and $(\mathrm{d})$ the need for employing statistical analysis to firstly filter the data (reject outliers) and secondly determine the propulsion system most frequent propeller curves and subsequently the main engine Most Frequently Occurring (MFO) operating points, for each MFO propeller curve.

For addressing these gaps, the present study focuses on the development of a novel systematic methodology for the vessel propulsion engine energy management. It is the first time that such a study is presented in the pertinent literature aiming to be used as a framework to drive the energy management analysis of the ship propulsion systems, leading to the identification of energy fuel saving initiatives with expected benefits for both academia and industry. The developed methodology is implemented for the cases of three different oceangoing cargo vessels, in specific a very large crude carrier (VLCC), a container ship and a bulk carrier, as these vessel types represent the $84.7 \%$ of the world fleet (UNTAD, 2017).

The remaining text is structured as follows. The investigated system description is provided in Section 2. Section 3 includes the description of the proposed systematic methodology. Section 4 discusses the results of the developed systematic methodology and summarises the proposed energy saving initiatives. Finally, Section 5 includes the conclusions drawn from this study.

\section{SYSTEM DESCRIPTION}

The major components of a typical energy system of oceangoing cargo vessels include the main (propulsion) engine, the diesel-generator sets and the boilers (auxiliary and/or exhaust gas waste heat recovery) as illustrated in Fig. 1. The propulsion engine can be of either the two-stroke type, which directly drives the ship propeller, or the four-stroke type that drives the propeller by the use of a gearbox (Wood \& Stapersma, 2002). The ship electrical energy is generated by the use of two to four generator sets, whereas the thermal energy demand is typically covered by producing saturated steam by using either a waste heat recovery (WHR) exhaust gas boiler, which recovers thermal energy from the main engine exhaust gas, or an oil-fired auxiliary boiler.

The propulsion (mechanical) energy corresponds to approximately $85 \%$ of the total ship energy demand (Baldi, et al., 2015; Dimopoulos \& Kakalis, 2014; Trivyza, et al., 2018), which justifies the focus of this study on the ship propulsion engine as, in this respect, more considerable energy savings are expected. The engine subsystems, components and their interconnections as well as the employed working media are also schematically illustrated in Fig. 1. The main engine components (Woodyard, 2003) include the engine cylinders block, the turbocharger (T/C), which consist of the compressor (C) and the turbine (T) connected in a common turbocharger shaft, the scavenge air cooler, the scavenge air receiver and the exhaust gas receiver. The engine service systems include the scavenge air cooler (SAC) cooling water system for the cooling hot air exiting the T/C compressor jacket cooling water (JCW) systems for the cooling of the cylinder block metallic parts, and lubricating oil (LO) system for reducing the friction and removing the heat due to friction from the engine moving/rotating components. 


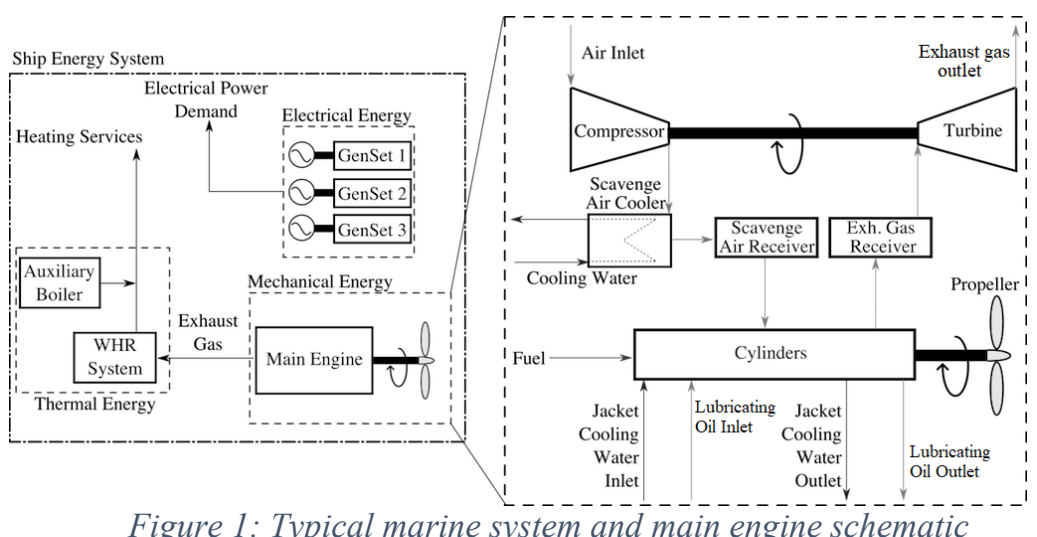

\section{METHODOLOGY DESCRIPTION}

\subsection{Methodology Steps}

The proposed in this study methodology was developed for systematically addressing the vessels main engine energy management by integrating a number of state-of-the-art tools including statistical analysis, compressor modelling and energy/exergy analysis. This methodology consists of five phases (listed in numerical order), each of which includes several stages (listed in alphabetical order). In additionally, each stage includes its own steps. The methodology phases and stages, which are graphically shown in Fig. 2, are listed as follows.

1. Data collection

A. Required Monitored Parameters (RMPs) recorded on-board are collected.

B. Baseline data is used to establish a basis for comparing the results of the exergy and energy analyses (in phase 4).

C. Miscellaneous data is acquired by using documents that provide information on the vessel main engine.

2. Preliminary analysis of data

A. Identification of the missing RMPs.

B. Correction of RMPs according to ISO standards and/or manufacturer guidelines whenever applicable.

3. Data analysis

A. Statistical analysis is employed using the engine power and speed, to identify the data in steady state, the MFO propeller curves and the MFO engine operating points.

B. Quality assessment of the RMPs is performed through a set of Key Performance Indicators (KPIs).

C. Prediction of the air mass flow rate by modelling the turbocharger compressor.

D. Derivation of the energy and exergy analyses required input data.

4. Energy and Exergy analyses

A. Derivation of the energy flows and the energy analysis KPI.

B. Derivation of the exergy flows, the exergy destruction and the exergy analysis KPI.

5. Energy saving initiatives

A. Evaluation and discussion of the derived results.

B. Evaluation of the vessel energy and fuel savings initiatives. 


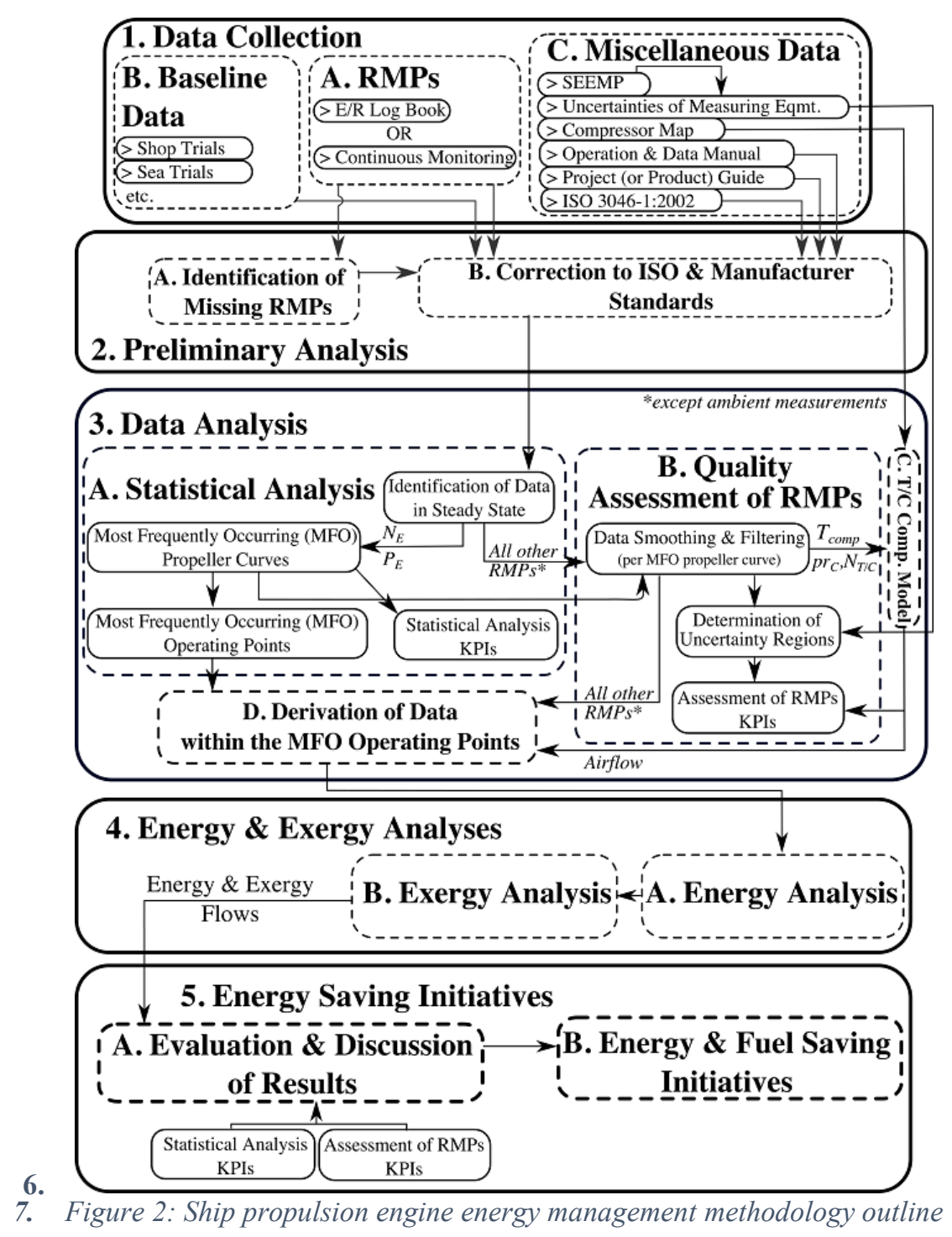

\subsection{Data Collection}

\subsubsection{Required Monitored Parameters}

The data collection stage includes the collection of the Required Monitored Parameters (RMPs) listed in Table 1, which need to be recorded on-board the vessel. Each RMP is associated with a rating, being characterised as either essential (denoted by E) or non-essential (denoted by N). The essential RMPs are absolutely necessary for implementing the systematic methodology proposed herein; however in the case where the non-essential RMPs are not available, they can be approximated by employing basic assumptions, so that the methodology can still be implemented.

\subsubsection{Baseline Data}

The Baseline Data stage refers to data that are processed in tandem with the RMPs and will be used in the Energy and Exergy Analyses phase for providing the baseline for comparison. The required data includes the parameters listed in Table 2, which can be collected from the following sources: (a) manufacturer look up tables 
(e.g. MAN Diesel \& Turbo CEAS (MAN Diesel \& Turbo, 2017) or WinGD GTD (WinGD, 2018)), (b) engine shop tests or sea trials, (c) RMPs previously collected (e.g. after the vessel drydock or the main engine overhaul), and (d) computer simulation results.

Table 1: Required Monitored Parameters

\begin{tabular}{|c|c|c|}
\hline Component & Required Monitored Parameters & Rating \\
\hline \multirow{4}{*}{ Engine } & Fuel Lower Heating Value (LHV) [kJ/kg] & $\mathrm{N}$ \\
\hline & Engine Rotational Speed [r/min] & $\mathrm{E}$ \\
\hline & Engine Power $[\mathrm{kW}]$ & E \\
\hline & Fuel Flow Rate $[\mathrm{kg} / \mathrm{h}]$ & $\mathrm{E}$ \\
\hline \multirow{3}{*}{ Ambient Conditions } & Engine Room Temperature $\left[{ }^{\circ} \mathrm{C}\right]$ & $\mathrm{E}$ \\
\hline & Engine Room Pressure [bar] & $\mathrm{N}$ \\
\hline & Scavenge Air Cooler(s) Cooling Fresh Water inlet Temperature $\left[{ }^{\circ} \mathrm{C}\right]$ & $\mathrm{E}$ \\
\hline \multirow{2}{*}{ Lubricating Oil Cooler } & Lubricating Oil Inlet Temperature $\left[{ }^{\circ} \mathrm{C}\right]$ & $\mathrm{N}$ \\
\hline & Lubricating Oil Outlet Temperature $\left[{ }^{\circ} \mathrm{C}\right]$ & $\mathrm{N}$ \\
\hline Jacket Water & Jacket Water Inlet Temperature $\left[{ }^{\circ} \mathrm{C}\right]$ & $\mathrm{N}$ \\
\hline \multirow{6}{*}{ Turbocharger(s) } & Rotational Speed [r/min] & $\mathrm{E}$ \\
\hline & Compressor Air Outlet Temperature $\left[{ }^{\circ} \mathrm{C}\right]$ & $\mathrm{E}$ \\
\hline & Turbine Exhaust Gas Inlet Temperature [ $\left.{ }^{\circ} \mathrm{C}\right]$ & $\mathrm{E}$ \\
\hline & Turbine Exhaust Gas Outlet Temperature $\left[{ }^{\circ} \mathrm{C}\right]$ & $\mathrm{E}$ \\
\hline & Turbine Back Pressure $[\mathrm{mm} \mathrm{WC}]$ & $\mathrm{N}$ \\
\hline & Air Filter Pressure Drop [mm WC] & $\mathrm{N}$ \\
\hline \multirow{3}{*}{ Scavenge Air Cooler(s) } & Air Outlet Temperature $\left[{ }^{\circ} \mathrm{C}\right]$ & $\mathrm{E}$ \\
\hline & Cooling Fresh Water Outlet $\left[{ }^{\circ} \mathrm{C}\right]$ & $\mathrm{N}$ \\
\hline & Air Pressure Drop [mm WC] & $\mathrm{N}$ \\
\hline Scavenge Air Receiver & Scavenge Air Pressure [bar] & $\mathrm{E}$ \\
\hline
\end{tabular}

Table 2: Baseline Data parameters

\begin{tabular}{|c|c|}
\hline Component/Category & Baseline Data Parameters \\
\hline \multirow{3}{*}{ Ambient Conditions } & Engine Room Temperature $\left[{ }^{\circ} \mathrm{C}\right]$ \\
\cline { 2 - 2 } & Engine Room Pressure $[\mathrm{bar}]$ \\
\cline { 2 - 2 } Engine & SAC(s) Cooling FW inlet temperature $\left[{ }^{\circ} \mathrm{C}\right]$ \\
\hline \multirow{4}{*}{} & Fuel Lower Heating Value $[\mathrm{kJ} / \mathrm{kg}]$ \\
\cline { 2 - 2 } & Engine Rotational Speed $[\mathrm{r} / \mathrm{min}]$ \\
\cline { 2 - 2 } & Specific Fuel Oil Consumption $[\mathrm{g} / \mathrm{kWh}]$ \\
\cline { 2 - 2 } & Turbine Exhaust Gas Temperature $\left[{ }^{\circ} \mathrm{C}\right]$ \\
\cline { 2 - 2 } & Engine Air Flow Rate $[\mathrm{kg} / \mathrm{s}]$ \\
\hline \multirow{3}{*}{ Engine Coolers } & Scavenge Air Cooler Heat Dissipation $[\mathrm{kW}]$ \\
\cline { 2 - 2 } & Jacket Water Cooler Heat Dissipation $[\mathrm{kW}]$ \\
\cline { 2 - 2 } & Main Lubrication Oil Heat Dissipation $[\mathrm{kW}]$ \\
\cline { 2 - 2 } & \\
\cline { 2 - 2 } & \\
\cline { 2 - 2 } &
\end{tabular}

\subsubsection{Miscellaneous Data}

The Miscellaneous Data stage includes the derivation of information for (a) the sensors installed onboard the vessel to record the RMPs, (b) the turbocharger compressor map, and (c) the engine service systems pumps flows and operating parameters. Specifically, the vessel engine operational manual provides information about the shipboard sensors based on which, the uncertainties of the recording equipment can be determined. The compressor map is often not available, however alternative modelling approaches for estimating the performance map of the marine engines turbocharger compressors can be employed (Llamas \& Eriksson, 2015; Llamas \& Eriksson, 2018; Guan, et al., 2014). The engine auxiliary systems (cooling water, lubricating oil) parameters including flow rates and temperatures can be estimated form the engine Project Guide and the engine Operation and Data Manual. 


\subsection{Preliminary Analysis}

The objective of the preliminary analysis phase is two-fold; firstly, the missing RMPs are identified, and secondly specific RMPs are corrected, when required, according to the corresponding ISO standards and/or the manufacturer guidelines to provide a common basis for comparison. In specific, the latter stage includes correcting the RMPs according to the guidelines of the engine Project Guide (MAN Diesel \& Turbo, 2010), the engine Operation \& Data Manual (MAN B\&W, 2007) and the ISO 3046-1:2002 (ISO 3016-1:2002, 2002) as indicated in Table 3.

As also noted in Table 1, the ambient pressure and turbine back pressure are non-essential parameters, meaning that their non-availability results in insignificant errors for the RMPs correction. Based on the correction formulae and the expected variation of the controlling parameters, the maximum errors were estimated; it was inferred that among the non-essential parameters, the back pressure is deemed as the most important and needs to be measured as it can provide useful information with regard to the fouling condition of the exhaust gas system and additionally, it adversely affects the engine performance (MAN Diesel \& Turbo, 2014).

Table 3: RMPs correction

\begin{tabular}{|c|c|c|}
\hline Corrected RMPs & Reference Document & RMPs used for correction \\
\hline Engine Power & ISO 3046-1:2002 & $\begin{array}{c}\text { Ambient temperature } \\
\text { Ambient pressure } \\
\text { SAC(s) inlet Cooling FW temperature }\end{array}$ \\
\hline $\begin{array}{l}\text { Fuel Flow Rate (or Specific Fuel } \\
\text { Oil Consumption) }\end{array}$ & ISO 3046-1:2002 & $\begin{array}{c}\text { Ambient temperature } \\
\text { Ambient pressure } \\
\text { SAC(s) inlet Cooling FW temperature }\end{array}$ \\
\hline $\begin{array}{c}\text { T/C Turbine Exhaust Gas Outlet } \\
\text { Temperature }\end{array}$ & $\begin{array}{l}\text { Project Guide / Operation } \\
\text { \& Data Manual }\end{array}$ & $\begin{array}{l}\text { Ambient temperature } \\
\text { Ambient pressure } \\
\text { SAC(s) inlet Cooling FW temperature } \\
\text { Turbine back pressure } \\
\end{array}$ \\
\hline Scavenge Air Pressure & Operation \& Data Manual & $\begin{array}{c}\text { Ambient temperature } \\
\text { SAC(s) inlet Cooling FW temperature }\end{array}$ \\
\hline T/C Rotational Speed & $\begin{array}{c}\text { SAE J1826 (SAE J1826, } \\
1995)\end{array}$ & Ambient temperature \\
\hline $\begin{array}{l}\text { T/C Compressor Outlet } \\
\text { Temperature }\end{array}$ & Operation \& Data Manual & $\begin{array}{c}\text { Ambient temperature } \\
\text { Compressor outlet air temperature }\end{array}$ \\
\hline $\mathrm{T} / \mathrm{C}$ Turbine Inlet Temperature & Operation \& Data Manual & $\begin{array}{l}\text { Turbine exhaust gas inlet temperature } \\
\text { Turbine exhaust gas outlet temperature }\end{array}$ \\
\hline
\end{tabular}

\subsection{Data Analysis}

The objectives of the Data Analysis phase are: (a) to identify the MFO propeller curves and the MFO engine operating points, (b) to quantitatively evaluate the RMPs quality, and (c) to derive the input parameters required for the energy and exergy analyses. As illustrated in Fig. 2, these objectives are achieved by: (a) developing and implementing a statistical analysis approach to identify the steady state operating periods, and subsequently determine the MFO propeller curves as well as the MFO engine operating points for each MFO propeller curve, thus estimating the actual engine operating profile, (b) assessing the RMPs quality whilst considering the uncertainties of the sensors used for the data acquisition, (c) filtering and smoothing the RMPs, (d) predicting the engine airflow by employing a $\mathrm{T} / \mathrm{C}$ compressor model, and (e) providing the required input to the energy and exergy analyses. 
The stages of this phase can be implemented for all the acquired data or for various data sets corresponding to consecutive time periods. In the latter case, the derived results can provide the evolution of the temporal variations of the MFO propeller curves, the acquired data assessment KPIs as well as the energy and exergy analyses parameters. These trends can be subsequently used for supporting decisions on required energy saving initiatives.

\subsubsection{Statistical Analysis}

The statistical analysis uses as input the engine speed and the corrected power along with additional user input data which includes (a) the maximum engine load rate of change (in percentage of the maximum continuous rating (MCR) load per hour) above of which, the engine is considered to operate in transient conditions, (b) the minimum value of $\mathrm{R}^{2}$ for accepting the fit of each voyage propeller curve (below of which, the fit is rejected), (c) the power and rotational speed at the engine MCR operational point, and (d) the data sampling rate (in number of measurements per day).

The steps of this phase, which are also illustrated in Fig. 3, are the following.

i. The data entries corresponding to the engine steady state operation are identified.

ii. The engine power versus speed data set is split into individual data sets corresponding to each vessel voyage. One voyage is defined as the travel from the origin to the destination port (i.e. the one leg of a round voyage).

iii. The data from each voyage is then fitted with a propeller curve function, which is parametrised by using two parameters.

iv. The propeller curve parameters derived from the previous step are treated as random variables, and their MFO values are calculated based on which, the MFO propeller curve(s) are determined.

v. The engine power versus engine speed data sets are categorised according to their respective propeller curve.

vi. Using the categorised engine power data, the probability distribution of the engine power for every MFO propeller curve is derived, the MFO engine operating points are determined and the engine operating profile is estimated. 


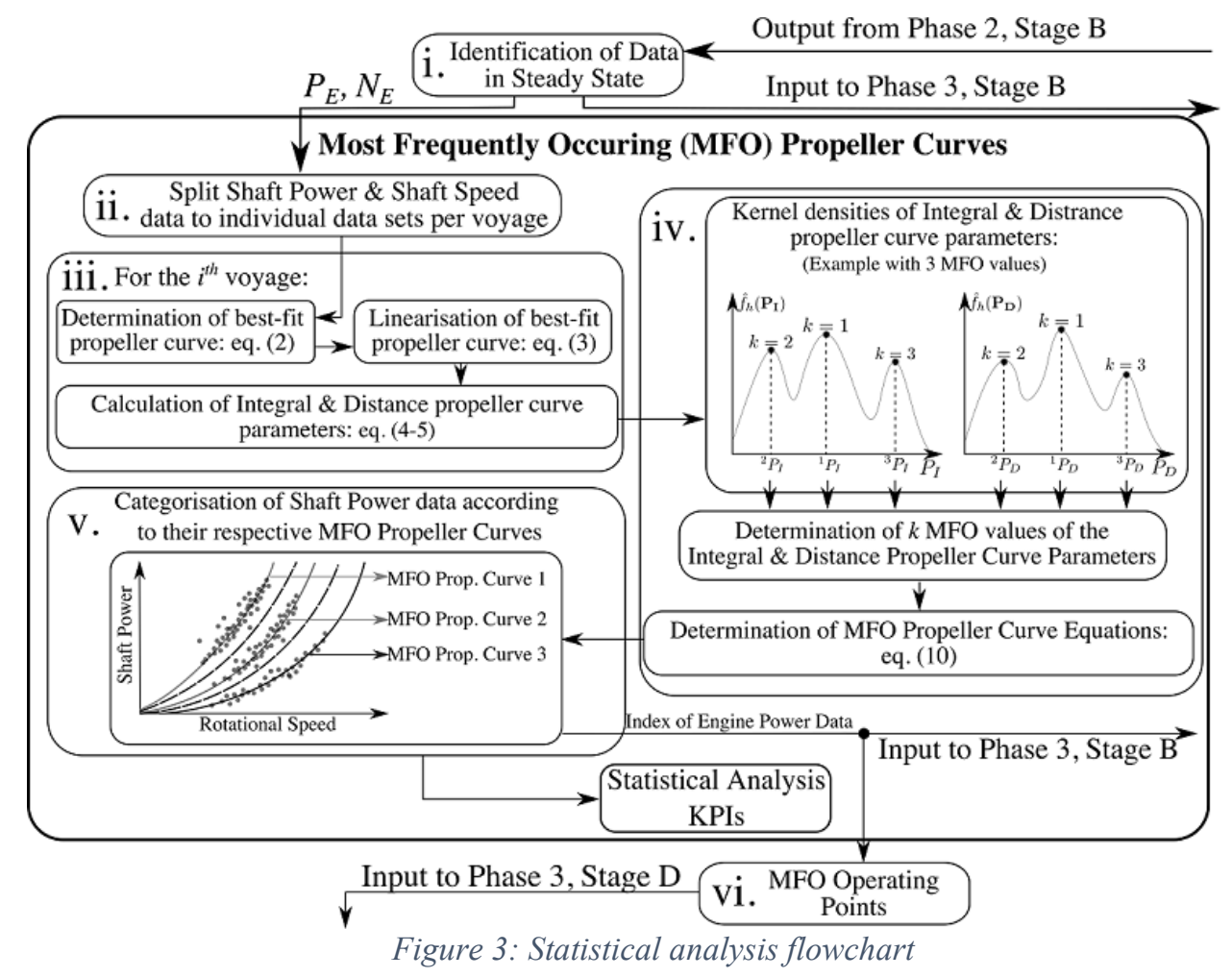

\section{Identification of Data in Steady State Conditions}

The procedure firstly includes the identification of the steady state and transient engine operating conditions by employing the engine load time derivative as provided by the following equation:

$$
\frac{100 \Delta P_{E}}{P_{E, \mathrm{MCR}} \Delta t}>c_{\text {user }}
$$

where $\Delta \mathrm{P}_{\mathrm{E}}$ denotes the change of the engine power, $\mathrm{P}_{\mathrm{E}, \mathrm{MCR}}$ denotes the engine power at $\mathrm{MCR}$, and $\Delta t$ denotes the time step.

The engine operating points with load below 10\% of MCR are also considered to correspond to transient conditions (MAN Diesel \& Turbo, 2010). This procedure is carried out only in the cases where the data sampling rate exceeds four entries per day. For smaller sampling rate values, all data are assumed to correspond to steady state conditions as not enough information is available for categorising the data sets. As proposed by the engine manufacturer (MAN Diesel \& Turbo, 2010), typical load changes occur with a slope of 5\% of MCR power per hour; therefore this value was taken into account for the case studies presented in the following sections. The number of data entries at transient operating conditions is used as a KPI to determine the percentage of the engine operation in steady state conditions.

\section{Split of Engine Power \& Engine Speed to Smaller Data Sets}

The second step includes the split of the engine power and rotational speed data set into smaller data sets on a per-voyage basis and fitting one propeller curve function for each data set. Each voyage is identified by considering the periods where the measured engine power and engine speed are zero. 


\section{Determination of Best-Fit Propeller Curves \& Propeller Curve Parameters}

In the third step, a propeller curve function, which is determined by the following equation (Carlton, 2007) (MAN Diesel \& Turbo, 2011), is fitted for every data set corresponding to the $i^{\text {th }}$ voyage:

$$
P_{E}\left(N_{E}\right)_{i}=\alpha_{i} N_{E}^{e_{i}}
$$

where the coefficient $\alpha_{i}$ and the exponent $e_{i}$ are the two parameters of each propeller curve function.

The minimum $\mathrm{R}^{2}$ value for accepting a propeller curve fit needs to be provided by the user. In this study, the $\mathrm{R}^{2}$ threshold was set to be 0.5 , as the engine power versus engine speed data plots tend to exhibit a large scattering below this value. In this respect, the propeller law (eq. (2) with the value of exponent equal to 3 ) does not always provides the best fit, however the exponent values are expected to be very close to 3 (MAN Diesel \& Turbo, 2011), and therefore, the exponent $e_{i}$ is considered to vary in the range from 2.8 to 3.2. For rendering the propeller curve function algebraic manipulation easier, eq. (2) is transformed to a first order polynomial (linear function) by considering the natural logarithms of the two terms of eq. (2) (Heer \& Maussner, 2005). Thus, the following equation is derived:

$$
\mathrm{y}_{\mathrm{i}}=\mathrm{a}_{\mathrm{i}}+e_{i} \mathrm{x}
$$

where $\mathrm{a}_{\mathrm{i}}=\ln \alpha_{i}$ and $\mathrm{x}=\ln N_{E}$.

The number of the rejected propeller curves with values of $\mathrm{R}^{2}$ lower than the considered threshold for rejecting the data fit and the number of the rejected data entries corresponding to these propeller curves are used as KPIs to quantify the dispersion of the data, and subsequently the quality of the on-board data recording procedure.

\section{Estimation of MFO Propeller Curve Functions}

In the fourth step, the propeller curve function of eq. (3) is parametrised by considering the integral and the distance parameters. The former is determined by considering the definite integral of the engine power evaluated using two specific values of the engine rotational speed (namely $N_{h i}$ and $N_{l o}$ ) and represents the area under each propeller curve, whilst the latter represents the power difference evaluated using the same values of the engine rotational speed. The integral and the distance propeller curve parameters are estimated by using the following equations, respectively:

$$
\begin{gathered}
P_{I, i}=\int_{\ln N_{l o}}^{\ln N_{h i}}\left(\mathrm{a}_{\mathrm{i}}+e_{i} \mathrm{x}\right) d \mathrm{x}=\mathrm{a}_{\mathrm{i}}\left(\ln \frac{N_{h i}}{N_{l o}}\right)+e_{i} \frac{\left(\ln N_{h i}\right)^{2}-\left(\ln N_{l o}\right)^{2}}{2} \\
P_{D, i}=\mathrm{a}_{\mathrm{i}}+\left.e_{i} \mathrm{x}\right|_{\ln N_{l o}} ^{\ln N_{h i}}=\mathrm{a}_{\mathrm{i}}+e_{i}\left(\ln \frac{N_{h i}}{N_{l o}}\right)
\end{gathered}
$$

These propeller curve parameters are calculated for the propeller curve of every voyage. Furthermore, the limits of evaluation ( $N_{h i}$ and $N_{l o}$, respectively) are of great importance, as their selection affects the consistency of the probability distribution function (PDF) that the propeller curve parameters are fitted with, as explained below. In this respect, they were chosen to be a standard deviation away from the mean engine rotational speed of the whole data set, and calculated according to the following equations: 


$$
N_{h i}=\mu_{N_{E}}+\sigma_{N_{E}} \text { and } N_{l o}=\mu_{N_{E}}-\sigma_{N_{E}}
$$

where the $\mu$ and $\sigma$ are the mean and standard deviation of the engine rotational speed data points, respectively.

The integral and distance propeller curve parameters are treated as random variables, with their PDFs being approximated by a Gaussian Kernel Density Estimation (KDE) (Sheather, 2004), which is a non-parametric way to estimate the PDF of random variables that cannot be readily described by other conventional PDFs. The selection of this distribution was based on the fact that the integral and distance parameters PDFs are expected to be multimodal; hence, the Gaussian KDE is calculated by superimposing a number of Gaussian Distributions (Gramacki, 2018). The following equation are used to calculate the integral parameter PDF, $\left(\hat{f}_{h}\right)$ :

$$
\hat{f}_{h}\left(\mathbf{P}_{I}\right)=\frac{1}{\mathrm{Vh}_{I}} \sum_{i=1}^{\mathrm{V}} \frac{1}{\sqrt{2 \pi}} \exp \left\{-\frac{1}{2}\left(\frac{P_{I}-P_{I, i}}{h_{I}}\right)^{2}\right\}
$$

where $\mathbf{P}_{I}=\left[P_{I, 1}, P_{I, 2}, \ldots, P_{I, i}, \ldots P_{I, V}\right]$ is the integral parameter vector consisting of all integral parameter values calculated from the first voyage to the last voyage $V$.

It comes as an inherit drawback of the KDE that the value of the bandwidth, $h_{I}$, has to be optimal, as a large bandwidth would cause the KDE being over-smoothed, thus hiding features or maxima of the distribution, whereas choosing a small bandwidth value would result in a PDF with noise. For obtaining a sufficient performance of the distribution for a wide range of data sets, the Silverman's reference bandwidth (Sheather, 2004) was considered, which is estimated according to the following equation:

$$
h_{I}=0.9\left[\min \left(\frac{\operatorname{IQR}\left(\mathbf{P}_{I}\right)}{1.34}, \operatorname{std}\left(\mathbf{P}_{I}\right)\right)\right]^{-1 / 5}
$$

where IQR is the interquartile range of the random variable $\mathbf{P}_{\mathbf{I}}$. Having determined a bandwidth and fitted the integral propeller curve parameter with the $\mathrm{KDE}$, the $k$ most frequently occurring values corresponding to the local maxima of the KDE can subsequently be determined by using the following equation:

$$
{ }^{k} P_{I}=\operatorname{argmax}\left(\hat{f}_{h_{I}}\left(\mathbf{P}_{I}\right)\right)
$$

Equations (7) - (9) are also employed for the calculation of the distance parameter of the propeller curve, by substituting $\mathbf{P}_{I}$ with $\mathbf{P}_{D}$.

Having obtained the MFO integral and distance propeller curve parameter values, the MFO propeller curve coefficients and exponents can be subsequently estimated by using the following equation, which was derived by manipulating eq. (4)-(5):

$$
\left[\begin{array}{c}
\ln \left({ }^{k} \alpha\right) \\
{ }_{e} e
\end{array}\right]=\left[\begin{array}{cc}
\ln \frac{N_{h i}}{N_{l o}} & 0.5\left[\left(\ln N_{h i}\right)^{2}-\left(\ln N_{l o}\right)^{2}\right] \\
1 & \ln \frac{N_{h i}}{N_{l o}}
\end{array}\right]^{-1}\left[\begin{array}{c}
{ }^{k} P_{I} \\
{ }^{k} P_{D}
\end{array}\right]
$$

where $k$ denotes the $\mathrm{k}^{\text {th }}$ MFO propeller curve. 
Solving the above system $k$ times, the propeller curve coefficient ${ }^{k} \alpha$ and exponent ${ }^{k} e$ are obtained. In case where the difference between the power of two adjacent MFO propeller curves for the whole engine speed range is lower than $5 \%$ of the MCR power, the two data sets are merged and a single MFO propeller curve is fitted.

\section{Categorisation of Engine Power Data According to the MFO Propeller Curves}

The fifth step includes the categorisation of the engine power $\left(P_{E}\right)$ and engine speed $\left(N_{E}\right)$ to subsets, ${ }^{k} \mathbf{P}_{E}$, each of them corresponding to the respective MFO propeller curves such that: $P_{E}=\left\{{ }^{\mathbf{1}} \mathbf{P}_{E},{ }^{2} \mathbf{P}_{E}, \ldots{ }^{k} \mathbf{P}_{E}\right\}$ and $N_{E}=$ $\left\{{ }^{1} \mathbf{N}_{E},{ }^{2} \mathbf{N}_{E}, \ldots{ }^{k} \mathbf{N}_{E}\right\}$. In this way, the most frequently occurring main engine loads per MFO propeller curve can be identified.

In order for the data set of the engine power versus rotational speed to be categorised, the midpoint of the power difference between the adjacent propeller curve equations is calculated, as shown in Fig. 2 (step v). For example, if the $1^{\text {st }}$ and $2^{\text {nd }}$ MFO propeller curves are adjacent (i.e. there is no other MFO propeller curve in between), then the midpoint line between those would be defined according to the following equation:

$$
M_{1 \sim 2}=\frac{{ }^{1} P_{E}\left(N_{E}\right)-{ }^{2} P_{E}\left(N_{E}\right)}{2}
$$

The midpoint line is then used as the boundary between adjacent propeller curves, and thus the data can be linked to their respective MFO propeller curve as shown in Fig. 2. The electronic address (index) of the engine power data set belonging to each MFO propeller curve is saved and used to characterise the rest of the RMPs for each MFO propeller curve.

Finally in this step, the quality of fit vector, $\overrightarrow{q o f}$, that denotes the normalised distance of each point of the split data sets (engine power versus speed) from their corresponding MFO propeller curve, is calculated by using the following equation:

$$
\overrightarrow{q o f}=\frac{{ }^{k} P_{E}\left({ }^{k} \mathbf{N}_{\mathbf{E}}\right)-{ }^{k} \mathbf{P}_{\mathbf{E}}}{{ }^{k} P_{E}\left({ }^{k} \mathbf{N}_{\mathbf{E}}\right)}
$$

The quality of fit, $Q o F$, which consists of the mean and standard deviation of the quality of fit vector, is subsequently calculated using the following equation and employed for characterising the obtained data fit quality:

$$
\mathrm{QoF}=\operatorname{mean}(\overrightarrow{q o f}) \pm \operatorname{std}(\overrightarrow{q o f})
$$

In summary, the output from this stage of the methodology include (a) the number of the identified data entries in steady state conditions, (b) the number of the rejected voyages and their corresponding data entries, (c) the MFO propeller curve equations, (d) the quality of fit of the MFO propeller curves, and (e) the indices (or electronic address) of the RMPs corresponding to each distinct MFO propeller curve.

\section{Determination of the Engine MFO Operating Points}

The first step of this stage is similar to the MFO propeller curves estimation step, as the engine power of the split data set corresponding to each MFO propeller curve $P_{E}=\left\{{ }^{\mathbf{1}} \mathbf{P}_{E},{ }^{2} \mathbf{P}_{E}, \ldots{ }^{k} \mathbf{P}_{E}\right\}$, are treated individually as 
random variables: ${ }^{k} \mathbf{P}_{E}=\left[{ }^{k} P_{E, 1},{ }^{k} P_{E, 2}, \ldots{ }^{k} P_{E, v}\right]$. For each of these random variables, a Gaussian KDE is fitted using eq. (7)-(9) to define the most frequently occurring engine power values, which correspond to the MFO engine operating points.

In the second step, the ranges of the engine power values that include each MFO operating point are selected, as illustrated in Fig. 3 . The range ${ }^{k} R_{n}$, corresponding to the $n^{\text {th }}$ MFO operating point, are derived by considering the standard deviation of the values of ${ }^{k} \mathbf{P}_{E}$ between adjacent minima of the KDE using the following equation:

$$
{ }^{k} R_{n}=\operatorname{std}\left(\underset{j}{\operatorname{argmin}}\left[\widehat{f}_{h}\left({ }^{k} \mathbf{P}_{E}\right)\right] \leq{ }^{k} \mathbf{P}_{E} \leq \underset{j+1}{\operatorname{argmin}}\left[\widehat{f}_{h}\left({ }^{k} \mathbf{P}_{E}\right)\right]\right)
$$

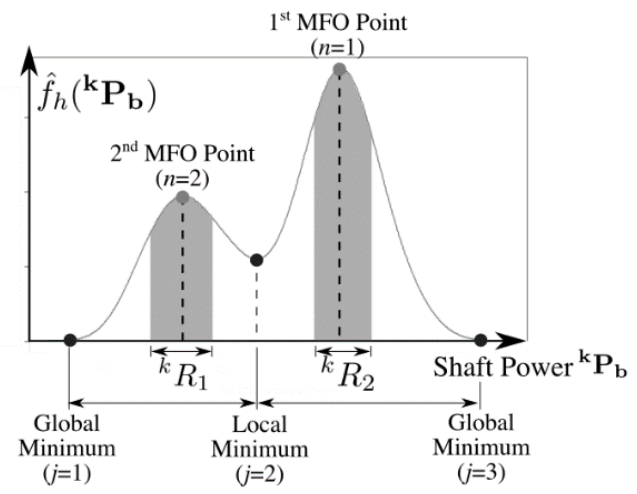

Figure 4: Range of engine power values inclusive of the MFO operation points

\subsubsection{Quality Assessment of Required Measured Parameters}

This stage includes the five steps illustrated in Fig. 5. The required input parameters include (a) all the RMPs corresponding to the steady state engine operation, except for the engine rotational speed and the ambient conditions, (b) the indices of the engine power data corresponding to each MFO propeller curve, (c) the uncertainties of the sensors used to record the RMPs, and (d) the load for activating/deactivating the engine auxiliary blower(s).

The first step includes splitting each RMP set in to two smaller data sets corresponding to engine loads below and above the auxiliary blower activation/deactivation load. In the second step, the index of the engine power data is used to further split the RPM data sets in accordance with the MFO propeller curves. In the third step, each individual set is smoothed using the robust local weighted scatterplot smoothing (RLOWESS) method (Siegmund, 1999). The optimum smoothing window is determined by using a variant of the sum of the absolute squares method. Multiple smoothing windows from $10 \%$ to $80 \%$ of the data are tested in increments of $5 \%$ and the smoothing window, in which the rate of change of the mean square error is minimised, is selected (Du \& Swamy, 2014). In the fourth step, the smoothed RMPs corresponding to each MFO propeller curve are derived. These will be further processed as described in the subsequent parts of the methodology to derive the input data for the energy and exergy analyses. The uncertainties of the measuring equipment are used to define the certainty zones as illustrated in Fig. 5, by considering a constant uncertainty zone or a percentage of uncertainty. The quality of each RMP is assessed by calculating the mean square error (MSE) between the RLOWESS fit and the scattered 
data points. In addition, the percentage of points outside the certainty zone is also calculated. These parameters are used as KPIs to quantitatively assess the dispersion of the data and the quality of the recorded RMPs.

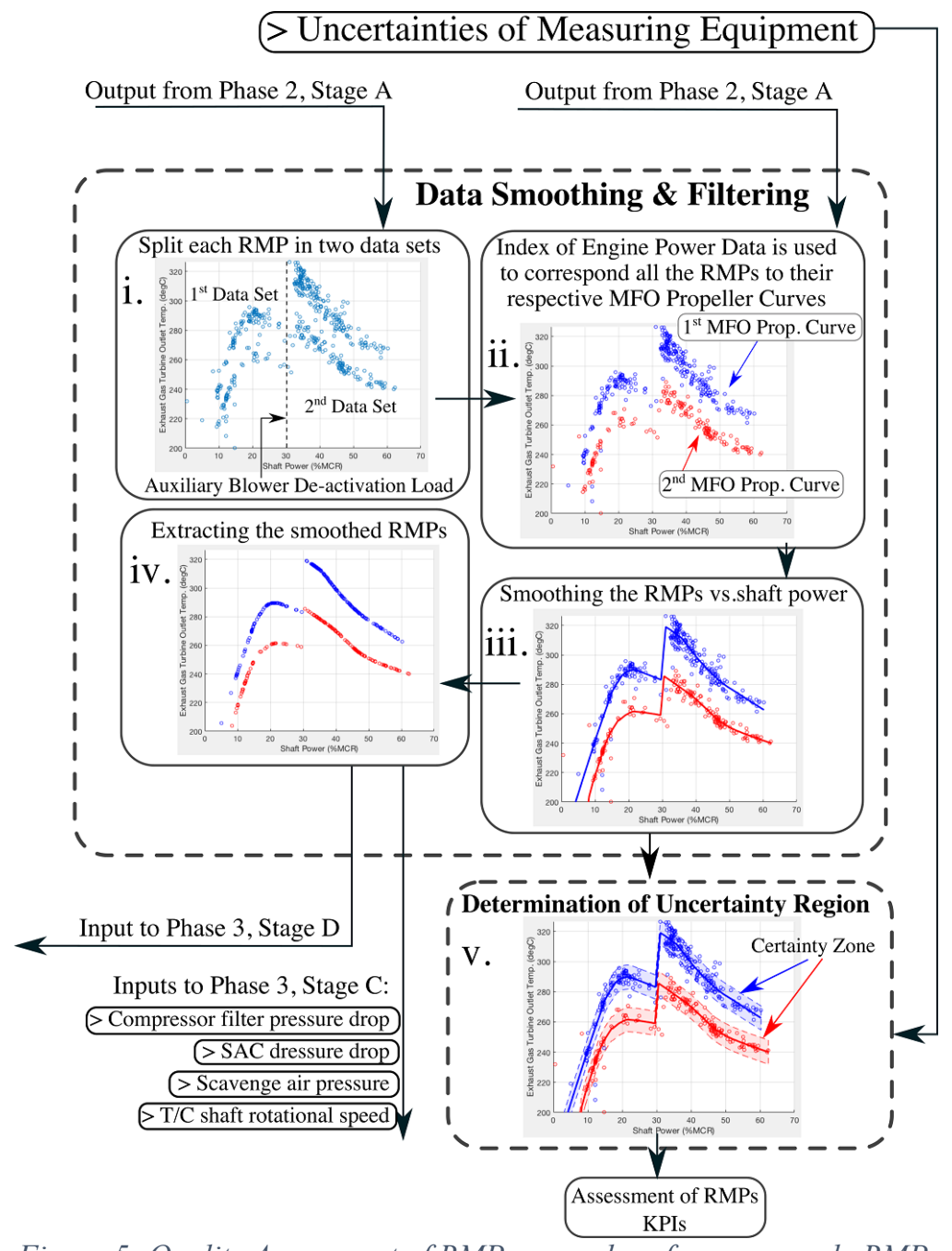

Figure 5: Quality Assessment of RMPs procedure for one sample RMP

\subsubsection{Prediction of Engine Air Flow}

For predicting the engine air flow, the following smoothed RMPs are used: (a) the air filter pressure drop, (b) the SAC pressure drop, (c) the scavenge air pressure, (d) the T/C rotational speed, and (e) the compressor outlet temperature. In addition, the compressor map needs to be provided or estimated (Llamas \& Eriksson, 2018; Llamas \& Eriksson, 2015), or alternatively, the compressor characteristic curve function (flow rate as a function of $\mathrm{T} / \mathrm{C}$ rotational speed, or pressure ratio) can be used.

In the first step of this stage, the T/C compressor is modelled by considering its compressor map. It must be noted that the compressor degradation was not considered in this study. The compressor map is provided in a digitised form, which includes the data points of pressure ratio, volumetric air flow rate and efficiency for a series of $\mathrm{T} / \mathrm{C}$ shaft rotational speed values. The compressor volumetric air flow, pressure ratio and rotational speed data points are fitted with a regression surface $\left(C_{M, \text { air }}\right)$, which correlates the volumetric air flow rate as a function of the compressor pressure ratio and the $\mathrm{T} / \mathrm{C}$ shaft rotational speed. A regression surface $\left(C_{M, \eta}\right)$ is also fitted to correlate the compressor map efficiency, the compressor pressure ratio and the $\mathrm{T} / \mathrm{C}$ shaft rotational speed data points. 
In the second step, the engine air mass flow rate is predicted. The pressure ratio is calculated using the appropriate RMPs according to the following equation:

$$
p r_{C}=\frac{p_{\text {scav }}+\Delta p_{S A C}}{p_{a m b, I S O}-\Delta p_{\text {filt }}} \approx \frac{p_{\text {scav,Cor }}}{p_{a m b, I S O}}
$$

Subsequently, the calculated pressure ratio and the measured $\mathrm{T} / \mathrm{C}$ shaft rotational speed are used as input to the regression surface function $\left(C_{M, a i r}\right)$ for calculating the compressor air flow rate according to the following equation:

$$
\dot{m}_{\text {air }}=\rho_{\text {air }} C_{M, a i r}\left(N_{T / C}, p r_{C}\right)
$$

In case where the engine includes more than one turbochargers, the engine air flow rate is calculated by summing the calculated air flows for each compressor.

By analysing the engine shop trials and typical values from the data available for a VLCC, it can be inferred that the compressor filter and scavenge air cooler pressure drops never exceed 3\% of the standard atmospheric pressure. Consequently, their effect on the calculation of the pressure ratio is considered to be insignificant. However, the above assumption is valid only in the case where the compressor filter or the scavenge air coolers are not considerably fouled. Nonetheless the above, assuming that such operating conditions are not encountered for the majority of the vessel operation, these two parameters may be excluded by the next stages of the methodology.

In the third step, the compressor efficiency values calculated from the compressor map fitted surface $\left(C_{M, \eta}\right)$ using the calculated pressure ratio and the smoothed $\mathrm{T} / \mathrm{C}$ rotational speed is compared with the respective values calculated by employing the following equation, which was derived using the compressor isentropic efficiency definition equation (Eriksson \& Nielsen, 2014) by using the measured compressor air outlet temperature and the calculated pressure ratio:

$$
\eta_{C, \text { calc }}=\frac{p r_{C}^{\frac{\gamma-1}{\gamma}}-1}{\left(T_{C} / T_{a m b, I S O}\right)-1}
$$

The mean square error between the predicted and the calculated efficiency values is then estimated, as well as the percentage of points that exceed the compressor map maximum efficiency. These parameters are used as KPIs to evaluate the quality of the respective measured data. For the cases where the calculated compressor efficiency exceeds the maximum compressor map efficiency, the compressor air outlet temperature is estimated by employing eq. (17) taking into account the predicted (by using the compressor map) efficiency and the calculated pressure ratio.

\subsubsection{Derivation of Filtered Data for the MFO Operating Points}

The objectives of this stage include: (a) to derive the filtered data that lie within the range ${ }^{k} R_{n}$ for each MFO operating point (shown in Fig. 4), and (b) to calculate their averaged values for each MFO operating point as shown in Fig. 6, which are used as the input for the energy and exergy analyses. 
In case where only a few data entries are available and thus a considerable data scattering is expected (e.g. noon reports), calculating the energy and exergy flows over the engine entire operating envelope introduces large uncertainties, as no data may be recorded for some engine load regions. For ensuring that a consistent cluster of data points is used for the calculation of the energy and exergy flows for each MFO engine operating point, the data points within the selected load ranges (for which a large number of measured data points are typically expected) are used.

The input for this stage calculations includes the smoothed and fitted RMPs (all measured temperatures and engine power) for each MFO propeller curve as well as the predicted engine air flow rate, whereas the calulations output parameters include the averages of the input parameters for each MFO engine operating point (within the considered load ranges).

In cases where the RMPs exhibit a uniform spread throughout the whole engine operating envelope, the user can choose to skip this stage of the methodology, thus calculating the energy and exergy flows along the whole engine operating envelope (and not only for the MFO operating points).

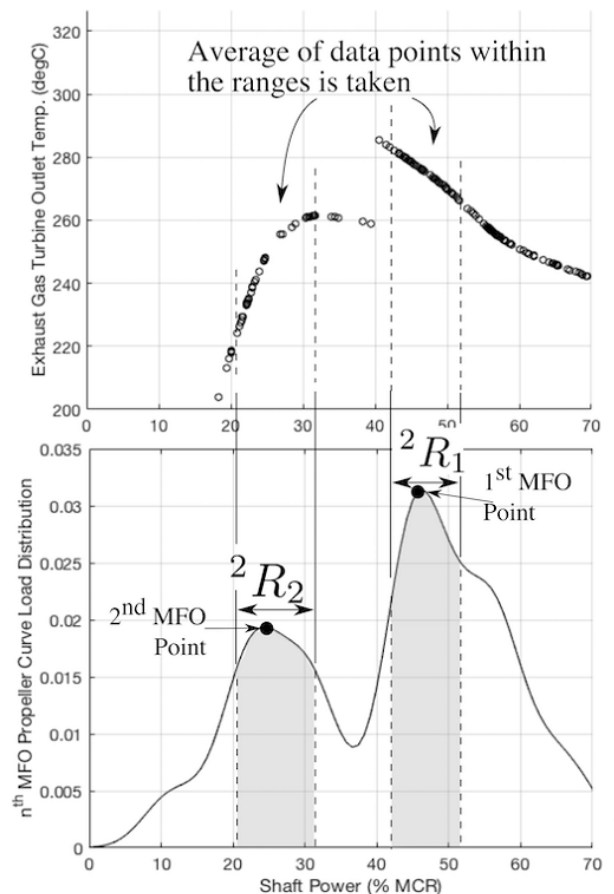

Figure 6: Filtered RMP within the considered range of the MFO engine operating points used for deriving the energy and exergy analyses input parameters

\subsection{Energy \& Exergy Analyses}

\subsubsection{Energy Analysis}

The scope of this stage is to derive the engine energy balance, the engine efficiency and the engine components heat flows as well as to provide the input parameters for the exergy analysis. Due to inaccuracies in the recorded RMPs, the difference between the calculated engine energy inflow and outflow is used as a KPI to characterise the accuracy of the energy analysis calculations. 
The input of the energy and exergy analyses include: (a) the averaged parameters within the selected range of every MFO operating point (obtained from phase 3-stage D), or the smoothed parameters for the whole envelope operating, (b) the main lubricating oil pump and jacket water pump capacities, and (c) the jacket water cooling thermostat setting.

Considering the first law of thermodynamics (Eriksson \& Nielsen, 2014), the total energy inflow (the fuel power) should be equal to the sum of thermal energy flows in the engine components, the radiation heat flow and the engine power output, as denoted by the following equation:

$$
\dot{Q}_{f u e l}=\dot{m}_{f u e l} L H V=\dot{Q}_{R a d}+\dot{Q}_{S A C}+\dot{Q}_{E x h}+\dot{Q}_{J C W}+\dot{Q}_{L O}+P_{E}
$$

As the fuel LHV is considered as a non-essential parameter, in cases where it is not available it can be taken as 40.8 MJ/kg for HFO and 42.7 MJ/kg for MDO (BEIS, 2016). Even if measured, the fuel LHV has a large uncertainty that can reach values up to $10 \%$ (Francesco Di \& Lazagni, 2017), which significantly impacts the accuracy of the energy balance calculations. However, an uncertainty analysis is not within the context of this study. The radiation heat flow $\dot{Q}_{R a d}$ is assumed to be $0.5 \%$ of the fuel power (Marty, et al., 2016).

By applying the first law of thermodynamics in the engine coolers (SAC, jacket water cooler and lubricating oil cooler), the following equation is derived for calculating the respective flow rates:

$$
\dot{Q}_{i}=\dot{m}_{i} c_{p, i} \Delta T_{i}
$$

where $i$ denotes the scavenge air cooler (SAC), the jacket water cooler $(J C W)$ and the lubricating oil cooler $(L O)$, $\dot{m}_{i}$ denotes the respective cooler working medium mass flow rate, and $\Delta T_{i}$ denote the respective cooler working medium temperature difference. In the case where the engine is equipped with more than one turbochargers the sum of the individual SAC heat flows is considered for calculating the total SAC heat flow.

The exhaust gas heat flow is calculated by the following equation:

$$
\dot{Q}_{E x h}=\left(\sum_{q=1}^{n} \dot{m}_{a i r, q}+\dot{m}_{f u e l}\right) c_{p, E x h}\left(\bar{T}_{E x h}-T_{a m b, I S O}\right)
$$

where $\bar{T}_{E x h}$ denotes the average temperature of the gas exiting the turbochargers turbines, $c_{p, E x h}$ is the exhaust gas specific heat at constant pressure and $\mathrm{n}$ denotes the number of turbochargers.

The specific heats at constant pressure of the air and the exhaust gas are calculated by considering the empirical formulas as reported by Keenan and Kaye (Marty, 2014). For calculating the jacket water cooling heat flow, the jacket cooling water thermostat temperature setting obtained from the Project Guide and the measured jacket cooling water inlet temperature are used, whereas for calculating the lubricating oil cooling heat flow, the measured lubricating oil inlet and outlet temperatures are employed. The volumetric flow rates of the jacket cooling water and main lubricating oil pumps are estimated using the figures provided in the engine Project Guide. It is then converted into the mass flow rate using the respective densities. Given that the jacket water cooling and lubricating oil energy flows represent less than 7\% of the fuel power (Marty, 2014), the error from the above assumption is expected to have a small impact. The specific heat capacity of the lubricating oil and cooling water and density are taken from (Torbacke, et al., 2014) and (IAPWS, 2007), respectively. 
Having calculated all the energy flows of eq. (18), the energy flows ratios for each term on the righthand side of eq. (18) are calculated as percentage of the fuel power. The energy analysis KPI is subsequently calculated using the following equation:

$$
\mathrm{KPI}_{\text {Energy }}=1-\frac{\left(\dot{Q}_{R a d}+\dot{Q}_{E x h}+\dot{Q}_{S A C}+\dot{Q}_{J C W}+\dot{Q}_{L O}+P_{E}\right)}{\dot{Q}_{\text {fuel }}}
$$

This KPI characterises the error between the calculated energy flow input and output. In cases where the jacket water and lubricating oil cooling heat flows cannot be determined as their respective RMPs are not available (Table 1), their sum is instead calculated by using eq. (18). In this case, the KPI of the energy balance cannot be calculated, and thus the accuracy of the energy analysis cannot be quantitatively assessed.

\subsubsection{Exergy Analysis}

The scope of this stage is to calculate the exergy flows and the engine components exergy destruction including the $\mathrm{T} / \mathrm{C}$ compressor, the scavenge air cooler, the engine block and the $\mathrm{T} / \mathrm{C}$ turbine in order to rank these components according to their share in the exergy destruction. The exergy destroyed is of key importance, as it represents the degradation of the energy quality of a working medium undergoing a thermodynamic process, thus indicating the sources of inefficiencies and the engine components losses, which the energy analysis fails to identify (Kotas, 1985) (Dimopoulos \& Kakalis, 2014). The input for this stage includes (a) all derived heat flows calculated in the energy analysis stage and, (b) all the energy analysis input parameters.

The total exergy destroyed in the engine is provided by the following equation, which can be derived by considering the exergy balance of the flows entering and exiting the control volume surrounding the engine as shown in Fig. 7:

$$
\dot{I}_{E}=\dot{E} X_{E, \text { in }}-\dot{E} X_{E, \text { out }}
$$

where:

$$
\begin{gathered}
\dot{E} X_{E, \text { in }}=\dot{E} X_{f u e l}+\dot{E} X_{J C W, \text { in }}+\dot{E} X_{L O, \text { in }}+\dot{E} X_{C W, \text { in }}+\dot{E} X_{\text {air }} \\
\dot{E} X_{E, \text { out }}=\dot{E} X_{C W, \text { out }}+\dot{E} X_{J C W, \text { out }}+\dot{E} X_{L O, \text { out }}+\dot{E} X_{E x h, \text { out }}+\sum_{q=1}^{n} P_{T / C, l o s s, q}+\dot{E} X_{R a d}+P_{E}
\end{gathered}
$$

The fuel exergy flow is calculated according to the following equation as reported in (Kaushik \& Singh, 2013):

$$
\dot{E} X_{\text {fuel }}=\dot{Q}_{\text {fuel }}\left[1.0401+0.1728 \frac{h}{c}+0.216 \frac{s}{c}\left(1-2.0628 \frac{h}{c}\right)\right]
$$

where $h, c$, and $s$ denote the fuel mass fraction in hydrogen, carbon and sulphur respectively. The following mass fractions are considered for the HFO fuel: $h=0.11 \mathrm{~kg}$ hydrogen per $\mathrm{kg}$ of fuel, $c=0.86 \mathrm{~kg}$ carbon per $\mathrm{kg}$ of fuel and $s=0.03 \mathrm{~kg}$ sulphur per $\mathrm{kg}$ of fuel (Kaushik \& Singh, 2013). The radiation of exergy is assumed to be $2 \%$ of the radiation heat flow according to (Dimopoulos \& Kakalis, 2014). 


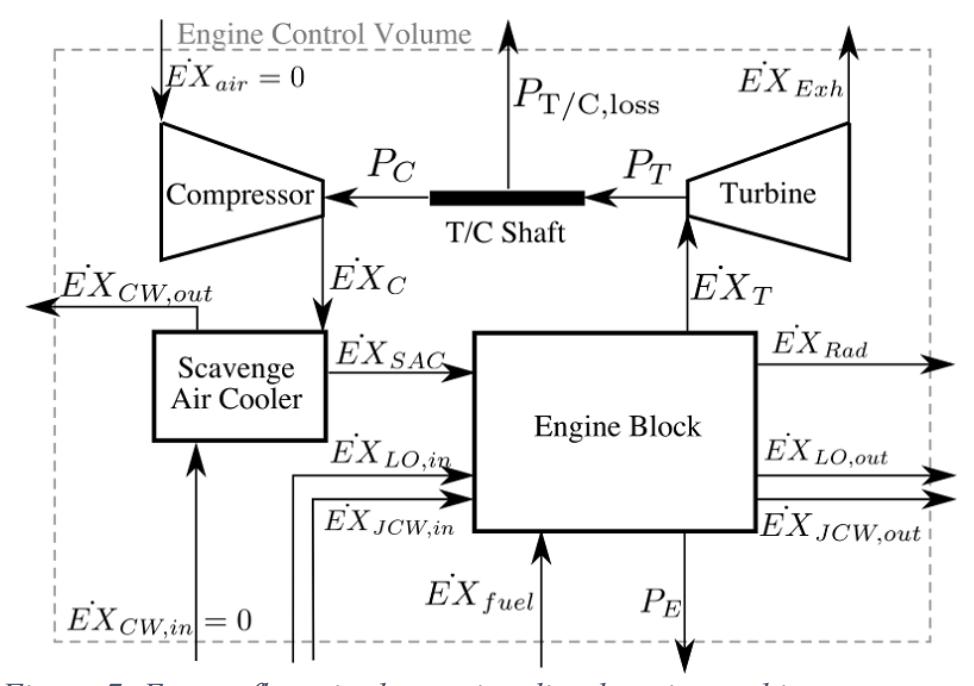

Figure 7: Exergy flows in the marine diesel engine and its components

The mechanical losses power for each turbocharger is calculated by using the energy balance of the turbocharger. The power of the turbocharger components (compressor, turbine) is calculated by using the following equation, which is derived by applying the first law of thermodynamics:

$$
P_{j}=\dot{m}_{j} c_{p, j} \Delta T_{j}
$$

where $j$ denotes the $\mathrm{T} / \mathrm{C}$ compressor $(\mathrm{C})$ and the $\mathrm{T} / \mathrm{C}$ turbine $(\mathrm{T}), \dot{m}_{j}$ denotes the respective air or exhaust gas mass flow rates, and $\Delta T_{j}$ denote the respective working medium temperature difference.

The remaining exergy flows of eq. (23)-(24) are calculated by using the following equation (Kotas, 1985):

$$
\dot{E} X_{i}=\dot{m}_{i} \Delta h_{i}\left(1-\frac{T_{a m b, I S O}}{T_{L M, i}}\right)
$$

where $\Delta h_{i}$ denotes the specific enthalpy change of the working fluid, and $T_{L M, i}$ is the average entropic temperature that is calculated using the following equation (Stewart \& Shelton, 2004):

$$
T_{L M, i}=\frac{T_{i}-T_{a m b, I S O}}{\ln \left(T_{i} / T_{a m b, I S O}\right)}
$$

Based on the fact that the reference temperature for the exergy analysis was assumed to be the ISO standard temperature and all input to the exergy analysis is corrected according to the ISO conditions, it can be deduced that the scavenge air cooler cooling water exergy inflow $\left(E X_{C W, i n}\right)$ and the $\mathrm{T} / \mathrm{C}$ compressor air exergy inflow $\left(E X_{\text {air }}\right)$ are equal to zero (the corresponding mean entropic temperature values calculated by eq. (28) approach the value of 1 and thus, these exergy inflows calculated from eq. (27) approach the value of 0). This is expected as in such cases the second thermodynamic law dictates that no useful energy can be generated from this flow and hence, its exergy flow is zero (Kotas, 1985).

To calculate the exergy destruction in each component, the exergy balance (eq. (22) applied for each engine component) is employed by considering the exergy inflows and outflows from the individual control volumes of compressor, turbine, SAC, and engine block (not shown in Fig. 7). For the case where the data for calculating the exergy flows of the jacket water cooling and the lubricating oil cooling are not available, then the eq. (23) - (24) can be considered without the respective terms. Due to the low temperatures involved in the jacket 
water and lubricating oil cooling systems, the exergy content of these flows is extremely low, usually in the order of less than 3\% (Marty, et al., 2016).

The exergy flows ratios and the exergy destruction share are calculated by using the following equations, respectively (Kotas, 1985):

$$
\psi_{i}=\frac{\dot{E} X_{i}}{\dot{E} X_{f u e l}} \text { and } \chi_{j}=\frac{\dot{I}_{j}}{\dot{E} X_{f u e l}}
$$

where the subscript $i$ refers to the radiation $(R a d)$, cooling water outlet $(C W$, out $)$, exhaust gas $(E x h)$, jacket cooling water outlet $(J C W, o u t)$ and lubricating oil outlet $(L O, o u t)$, whereas the subscript $j$ refers to the compressor, scavenge air cooler, engine block and turbine.

The exergy analysis calculation KPI is subsequently calculated according to the following equation and used for characterising the consistency of the performed calculations:

$$
K P I_{\text {Exergy }}=1-\sum_{i} \psi_{i}-\sum_{j} \chi_{j}
$$

\section{RESULTS AND DISCUSSION}

\subsection{Case Studies}

The developed methodology was implemented for three case studies, corresponding to three different vessel types, in specific for a very large crude carrier (VLCC), a container ship and a bulk carrier, based on the collected data employing two different data acquisition methods (noon reports and ADLM systems). As not all essential parameters were available for the case of the container ship and the bulk carrier, the methodology was implemented up to the Quality Assessment of RMPs and Statistical Analysis stages, respectively. The specific characteristics of the collected data are listed in Table 4.

Table 4: Characteristics of the vessels and the data collected for the 3 investigated case studies

\begin{tabular}{|c|c|c|c|}
\hline Vessel Type & VLCC & Container Ship & Bulk Carrier \\
\hline Engine type & 2-Stroke Diesel & 2-Stroke Diesel & 2-Stroke Diesel \\
\hline Engine MCR power (kW) & 29,300 & 51,100 & 18,700 \\
\hline $\begin{array}{c}\text { Drequency of data collection } \\
\text { (entries per day) }\end{array}$ & Noon reports & ADLM & 144 \\
\hline Data collection period (voyages) & 1 & 40 & 5 \\
\hline Total number of data entries & 654 & 734 & 13,608 \\
\hline $\begin{array}{c}\text { Data availability } \\
\text { be performed with the available } \\
\text { data }\end{array}$ & $\begin{array}{c}\text { Energy and Exergy } \\
\text { Analyses }\end{array}$ & $\begin{array}{c}\text { Quality Assessment } \\
\text { of RMPs }\end{array}$ & $\begin{array}{c}\text { Statistical Analysis } \\
\text { rated) RMPs are } \\
\text { unavailable }\end{array}$ \\
\hline
\end{tabular}

\subsection{Most Frequently Occurring Propeller Curves}

The best-fit propeller curves per voyage are plotted for the three investigated vessel types as shown in Fig. 8. As mentioned in the preceding sections, the acceptable fitted curves correspond to $\mathrm{R}^{2}$ values above 0.5 . In specific, the following $\mathrm{R}^{2}$ ranges were obtained for the three investigated vessels presented in Fig. 8. For the 
VLCC vessel, 0.58-0.995 with an average of 0.81; for the containership, 0.864-0.998 with an average of 0.958; and for the bulk carrier, 0.731-0.907 with an average of 0.82. The greater $\mathrm{R}^{2}$ values for the case of the containership denote a better quality of the recorded data, whereas the VLCC exhibited the lowest $\mathrm{R}^{2}$ values and the largest data fits percentage with $\mathrm{R}^{2}$ values lower that the set threshold for the fit rejection.
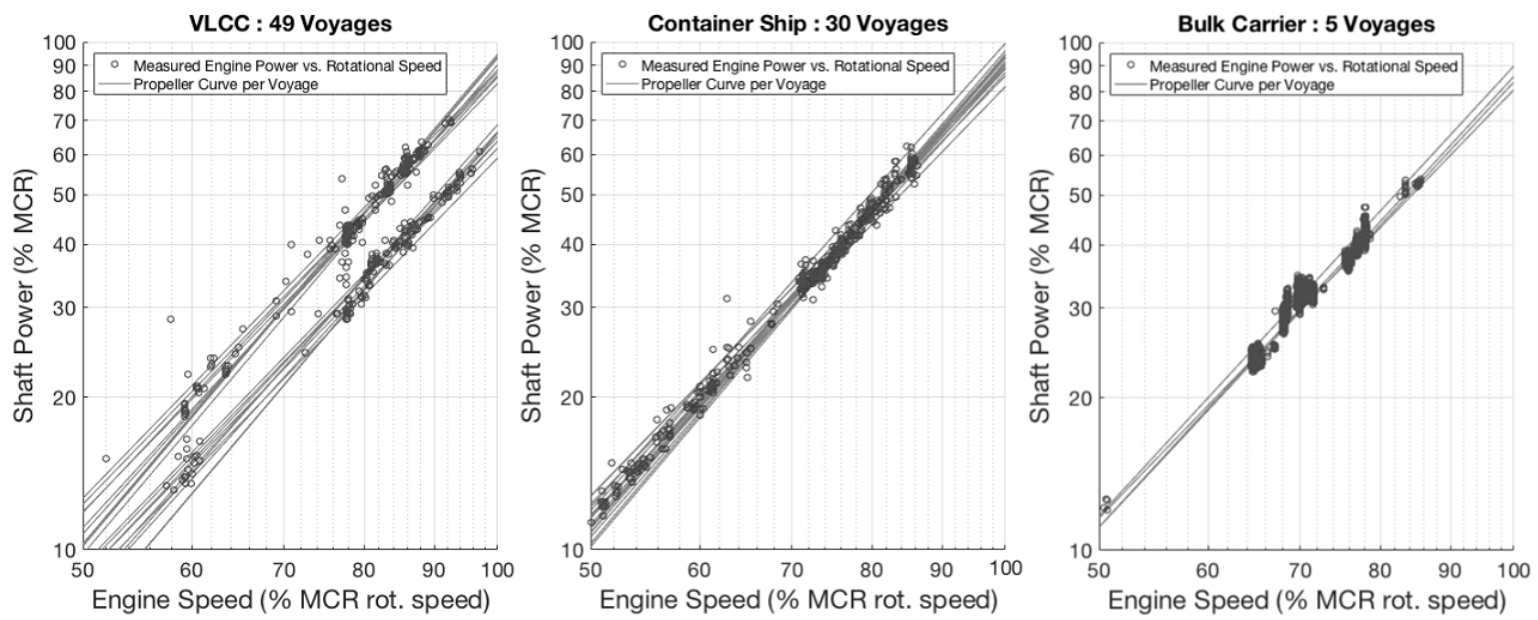

Figure 8: Best-fit propeller curves per voyage
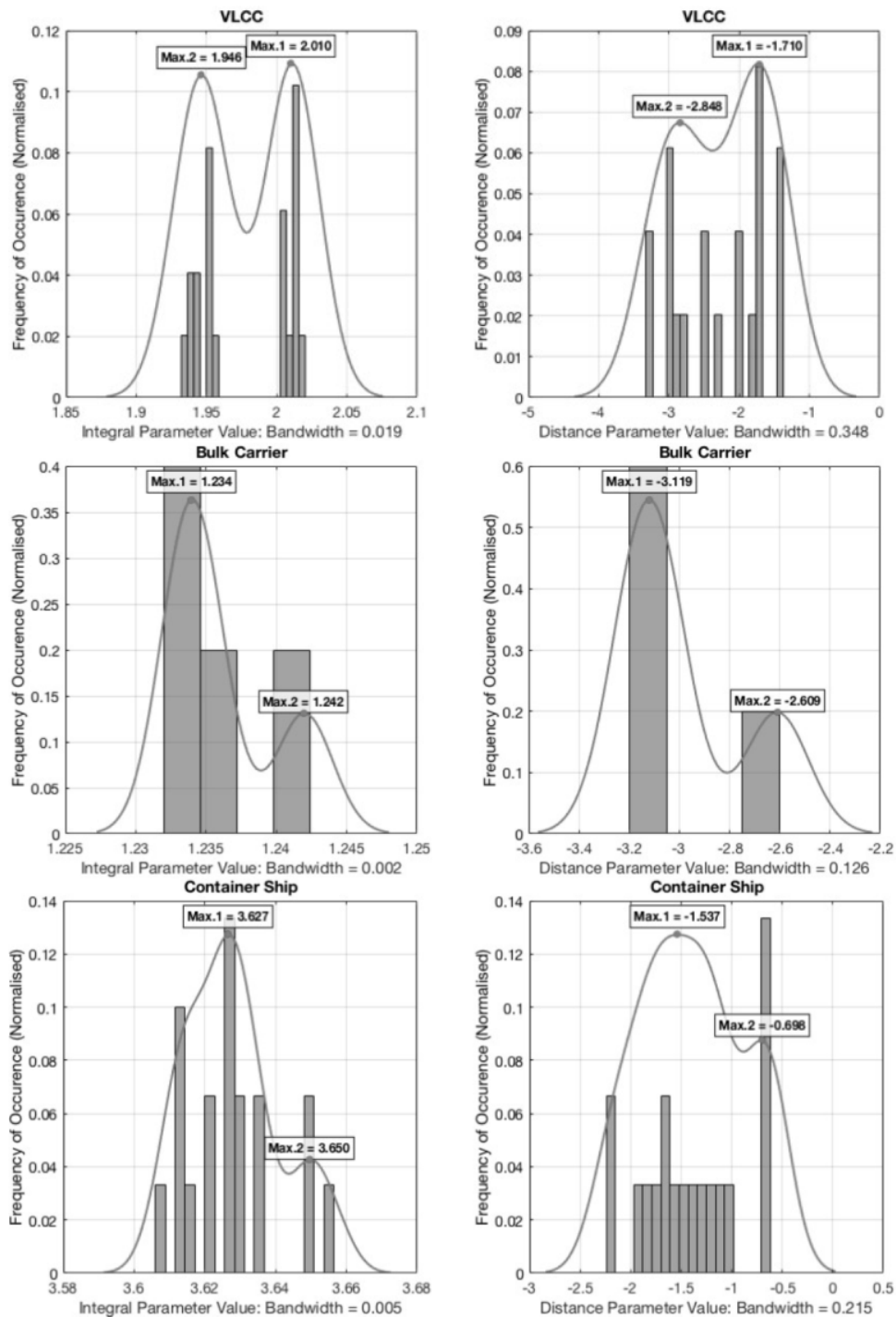

Figure 9: KDE plots and MFO integral and distance parameter values for the investigated vessels 

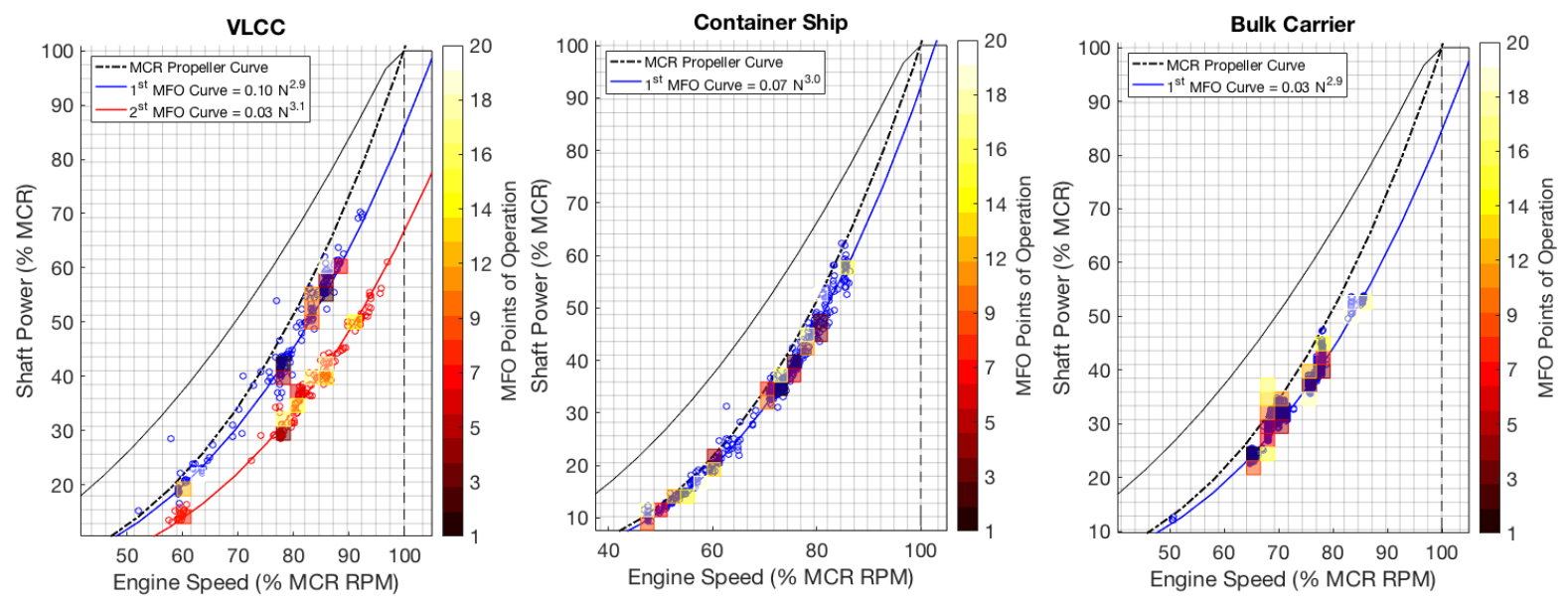

Figure 10: Estimated MFO propeller curves and MFO engine operating points (the coloured patches indicate

the most frequent engine operating points from the $1^{\text {st }}$ to the $20^{\text {th }}$ )

For the case of the VLCC, two distinct clusters of propeller curves were derived, contrary to the other two vessels where one cluster of propeller curves was derived, indicating the differences in the operational profiles of the three investigated vessels. The MFO propeller curves were subsequently estimated, by calculating the MFO values of the integral and distance propeller curve parameters, which are shown in Fig. 9. For all the investigated vessels, the propeller curve parameters KDEs exhibit two distinct MFO values each, which demonstrates that two MFO propeller curves are expected. However, for the case of the container ship and bulk carrier, the MFO propeller curves derived are closer than $5 \%$ of the MCR power to each other for all engine speed values, hence their average is considered for the estimation of the resultant MFO propeller curve.

The calculated MFO propeller curves and the propeller curve passing through the engine MCR point superimposed on the engine load layout diagram for each investigated vessel are shown in Fig. 10. In the VLCC case, two distinct MFO propeller curves were estimated, which is attributed to the fact that the VLCC sails in either laden (transporting crude oil) or ballast conditions with a significant difference in the resistance of the vessel due to the variation in her draft. Consequently, the $1^{\text {st }}$ MFO propeller curve which is steeper, corresponds to the laden conditions, whilst the $2^{\text {nd }}$ MFO propeller curve corresponds to the ballast conditions where the propeller runs in lighter conditions. In this case, the VLCC most frequently operates in laden conditions, which is closer to the propeller curve that passes through the MCR. However, referring to Fig. 9, the small differences in the peaks of the plotted KDEs denote that the operational time between the ballast and the laden conditions is almost evenly split.

For the container ship and the bulk carrier cases, only one MFO propeller curve was estimated. As the the container ship typically sails on regular round voyages at laden conditions, the only significant changes in resistance might be due to fouling or weather conditions that vary in a stochastic basis. For the case of the bulk carrier, it is deduced from the data analysis that the ship sails in both laden and ballast conditions; however there is no significant change in the propeller curve steepness. It is therefore inferred that the bulk carrier transports cargo of light specific gravity resulting in only slight draft variation between the laden and ballast conditions; thus, there is no considerable change in the ship resistance and as a consequence, in the estimated MFO propeller curve. 
The derived propeller curve parameters are given in Table 5. For all of the estimated MFO propeller curves, it is observed that the derived equations sufficiently follow the propeller law, with the calculated exponents being very close to or equal to 3 .

Table 5: Parameters of propeller curves derived for the three case studies.

\begin{tabular}{|c|c|c|c|c|}
\hline Vessel & $\begin{array}{c}\text { VLCC } \\
\mathbf{1}^{\text {st }} \text { MFO Prop. } \\
\text { Curve }\end{array}$ & $\begin{array}{c}\text { VLCC } \\
\text { 2 }^{\text {MFO Prop. }} \\
\text { Curve }\end{array}$ & Container Ship & Bulk Carrier \\
\hline Coefficient & 0.10 & 0.03 & 0.07 & 0.03 \\
\hline Exponent & 2.9 & 3.1 & 3.0 & 2.9 \\
\hline
\end{tabular}

\subsection{Most Frequently Occurring Operating Points}

The derived main engine operating profiles (KDEs) of each MFO propeller curve for the investigated vessel types are plotted in Fig. 11. The VLCC main engine most frequently experiences loads of $42 \%$ and $56 \%$ of its MCR when operating in the $1^{\text {st }}$ MFO propeller curve (laden conditions), whereas the operating point at $37 \%$ load is the MFO, corresponding to the $2^{\text {nd }}$ MFO propeller curve (ballast conditions). This can be also deduced from the coloured grid patches shown in Fig. 10, which indicate the most frequent occurring operating points (from the first to the twentieth). A similar trend is also observed for the container ship and the bulk carrier operating profiles, indicating that in most cases, their engines operate at loads much lower than 50\%. Therefore, it can be inferred that these vessels operators have implemented slow steaming (to reduce fuel consumption). However, even if the direct fuel savings might be significant, the engines operate in the region of low efficiency as typically the highest engine efficiency is obtained at much higher loads (75\%-85\%) (Theotokatos \& Tzelepis, 2015) (Guan, et al., 2014).
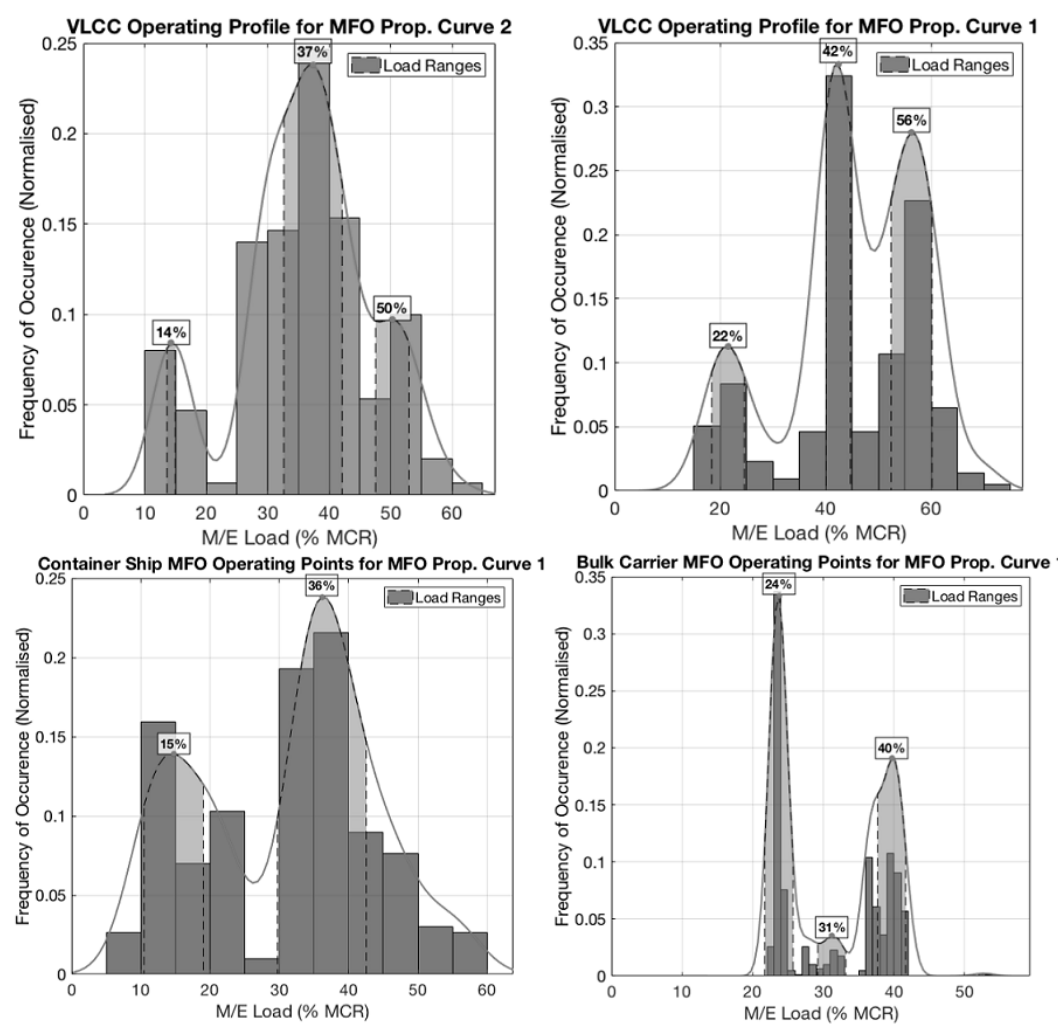

Figure 11: MFO operating points per MFO propeller curve for the investigated vessels 


\subsection{Statistical Analysis Key Performance Indicators}

The statistical analysis KPIs derived for the three investigated vessels shaft power versus engine speed data (referred to as the data in this section) are presented in Table 6 . These KPIs indicate a better data quality for the cases of the container ship and the bulk carrier as compared to the case of the VLCC. It can be observed that a considerable percentage of data points was rejected in the case of the VLCC, which indicates that there is a larger scattering effect of the VLCC data contrary to the data of the other two vessels.

For the VLCC case, the transient conditions time percentage cannot be identified as the sampling rate is one data point per day. However, for the other two vessels, $6 \%$ and $9 \%$ of the data points correspond to the transient operation respectively, as the load change limit of 5\% MCR per hour is exceeded. Hence, this KPI demonstrates that for the largest part of their voyage, these vessels sail with their engines operating at steady state as expected for ocean going vessels, for which the steady state operation is the dominant mode of their engine operating profile.

In addition, a better quality of fit (QoF) was obtained for the MFO propeller curves in the cases of the container ship and the bulk carrier. This KPI characterises the performance of the statistical analysis itself and quantifies the data scattering. For example, for the case of the bulk carrier, the first term of QoF is calculated as $-0.5 \%$, which denotes that the data lies on average $0.5 \%$ underneath the fitted MFO propeller curve. The second term of the QoF was calculated as $2 \%$, which implies that $34.1 \%$ ( 1 standard deviation) of all the measured data lies within $2 \%$ distance from the MFO propeller curve.

The above differences are attributed to the fact that noon-reports were used for recording the data manually for the VLCC case, whilst an ADLM system with no human intervention was employed in the other two vessels. As expected the manual recording of the propulsion engine parameters resulted in the deterioration of the collected data quality. Overall the statistical analysis derived KPIs seem to be a useful tool for the characterisation of the recorded data quality as well as for revealing the attributes of the main engine operating profile.

Table 6: Statistical analysis KPIS

\begin{tabular}{|c|c|c|c|}
\hline Vessel Type & VLCC & Container Ship & Bulk Carrier \\
\hline Rejected voyages number / ( Total voyages number) & $29 /(49)$ & $12 /(30)$ & $1 /(5)$ \\
\hline $\begin{array}{c}\text { Percentage of rejected data points number } \\
\text { corresponding to voyages }\end{array}$ & $26 \%$ & $10 \%$ & $14 \%$ \\
\hline $\begin{array}{c}\text { Data points in transient condition; engine load } \\
\text { variation > 5\% MCR/h }\end{array}$ & $\mathrm{N} / \mathrm{A}$ & $6 \%$ & $9 \%$ \\
\hline $\mathbf{1}^{\text {st }}$ MFO propeller curve Quality of fit $(\mathrm{QoF})$ & $-2.5 \% \pm 6.5 \%$ & $1.1 \% \pm 3.1 \%$ & $-0.5 \% \pm 2.0 \%$ \\
\hline $\mathbf{2}^{\text {nd }} \mathbf{M F O}$ propeller curve Quality of fit $(\mathrm{QoF})$ & $-0.8 \% \pm 5.4 \%$ & $\mathrm{~N} / \mathrm{A}$ & $\mathrm{N} / \mathrm{A}$ \\
\hline
\end{tabular}

\subsection{Quality Assessment of RMPs}

Having assessed the quality of the shaft power versus engine speed data, the quality of the other RMPs is subsequently assessed considering the uncertainties/errors of the sensors employed to record these parameters. Data from the VLCC and the container ship are only available and thus analysed in this section. The derived KPIs 
including the normalised root mean square error (MSE) and the percentage of points outside the certainty zone for a number of the available RMPs are presented in Fig. 12. The latter was estimated taking into account the uncertainties of the employed sensors (MAN Diesel \& Turbo, 2010; MAN B\&W, 2007). A number of the recorded RMPs with the largest MSE and percentage of points outside the certainty zone along with the derived averaged (smoothed) values and the parameters uncertainty zones are presented in Fig. 13. Based on these results, the quality of the RMPs recorded for the cases of the VLCC (from noon reports) and the containership (employing an ADLM system) can be evaluated.

The scavenge air pressure, the T/C compressors outlet temperature and the scavenge air coolers cooling water outlet temperature exhibited the largest values of root mean square error for the VLCC case (in specific, $16.3 \%, 8.0 \%$ and $7.9 \%$, respectively), whereas the second $\mathrm{T} / \mathrm{C}$ compressor outlet temperature, the fuel mass flow, the scavenge air pressure and exhibited the largest mean square error values for the container ship case (in specific, $16.0 \%, 5.2 \%$ and $4.8 \%$, respectively). This indicates that a larger data dispersion must be expected for these RMPs. For the VLCC case, the T/Cs rotational speed and both T/Cs compressors air outlet temperature measurements exhibited the largest percentage of data points lying outside the certainty zone, in specific $45.4 \%$ and $44.9 \%$, respectively. This KPI indicates that the data dispersion exceeds the uncertainty limits of the equipment used to record the given RMPs. Most importantly for both cases, a large number of points outside the certainty zone indicates a considerable inaccuracy of the sensors and/or the recording system used to measure the respective RMP. However, the present analysis does not account for systematic errors or offsets that could uniformly shift the trend of a given RMP. It should be noted that uncertainty analysis is out of the scope of this study, and the uncertainties should be provided as a user input to the methodology.
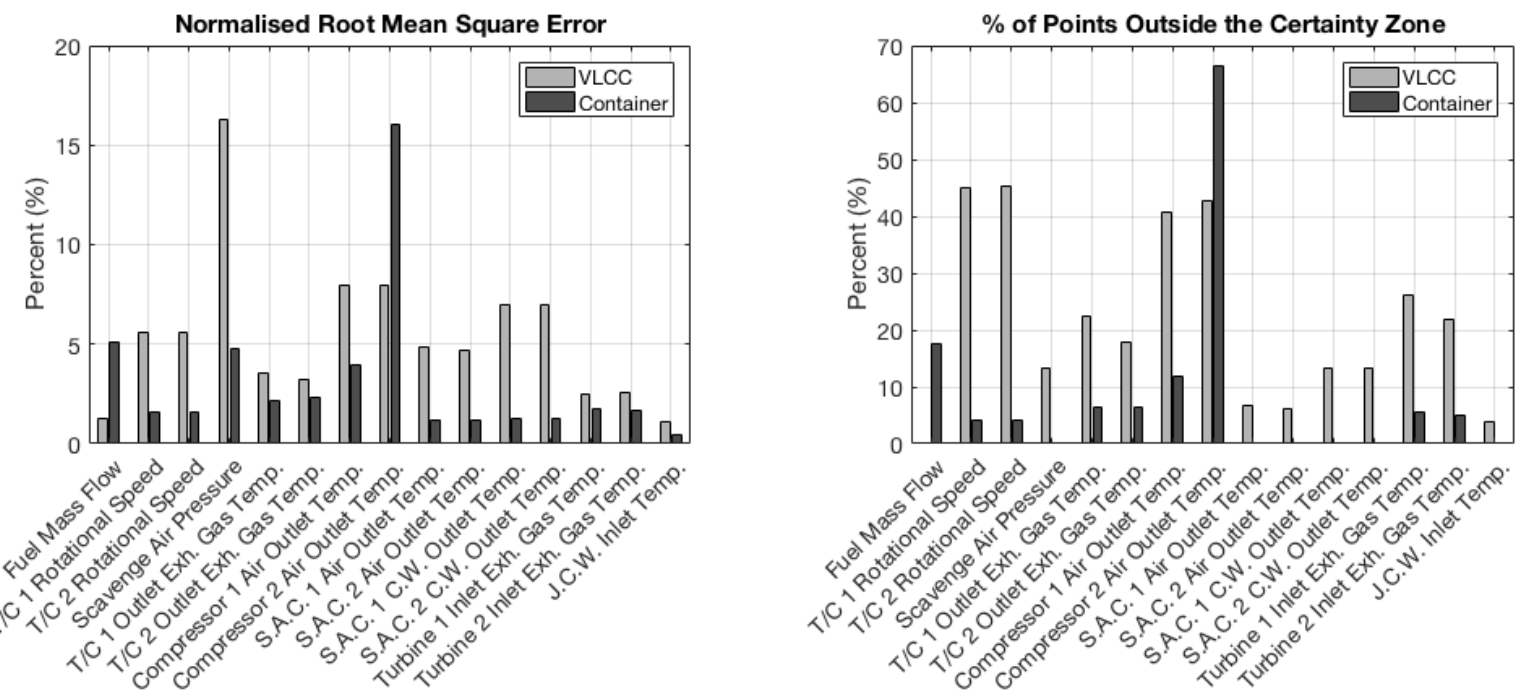

Figure 12: Recorded RMPS quality assessment KPIs for the VLCC and the container ship

For the container ship case, the T/C No. 2 compressor air outlet temperature exhibits a completely different behaviour (the root mean square error was $16 \%$, whereas the percentage of points outside the certainty zone was $66.3 \%$ ) compared with the respective parameters of $\mathrm{T} / \mathrm{C}$ No. 1 compressor, whilst the other $\mathrm{T} / \mathrm{C}$ parameters exhibit similar behaviour (although some small differences are observed). For the T/C No. 2 compressor air outlet temperature, neither the smoothed average nor the certainty zone have superimposed in the respective plot shown in Fig. 13. This is because two different trends can be distinguished; one at higher temperature values and another at lower temperature values. As the pressure ratio is almost the same in all the 
engine turbochargers (which are connected in parallel) and additionally the recorded values of T/Cs shafts speed are similar, a change in the compressor efficiency (due to compressor fouling or wear) can only justify the different values of the compressor outlet temperatures (assuming that there are not issues with the temperature sensor). It is reported in the literature that due to the strict schedule of ship, only a number of the engine turbochargers is often maintained during the ship staying at the port, resulting in engine operation with a number of turbochargers fouled (Livanos, et al., 2003), which coincides with the findings for the present study. Further analysis, of this parameter percentage error from the average value corresponding to the engine load as function of time (not shown herein) indicated periods of maintenance actions (inferred from the error sign changes) possibly compressor washing/cleaning. In this case, the derived KPIs as well as the estimated compressor efficiency can be used for identifying initiatives related with maintenance actions or faulty sensors.

With the exception of the T/C No. 2 compressor air outlet temperature, all the other parameters exhibited lower values in the derived KPIs for the case of the containership. This indicated that the quality of the recorded parameters is much more improved in case where an ADLM system is used instead of the manually recorded noon report practices. In both data acquisition cases, the proposed methodology and the derived KPIs are capable of providing the required information for the quantitative assessment of the recorded parameters leading to identification of sensors faults (in cases where large data dispersion) or engine components with degraded performance (in cases of deviation of the parameters from their baseline or average values). 
VLCC Measured Parameter T/C no. 2
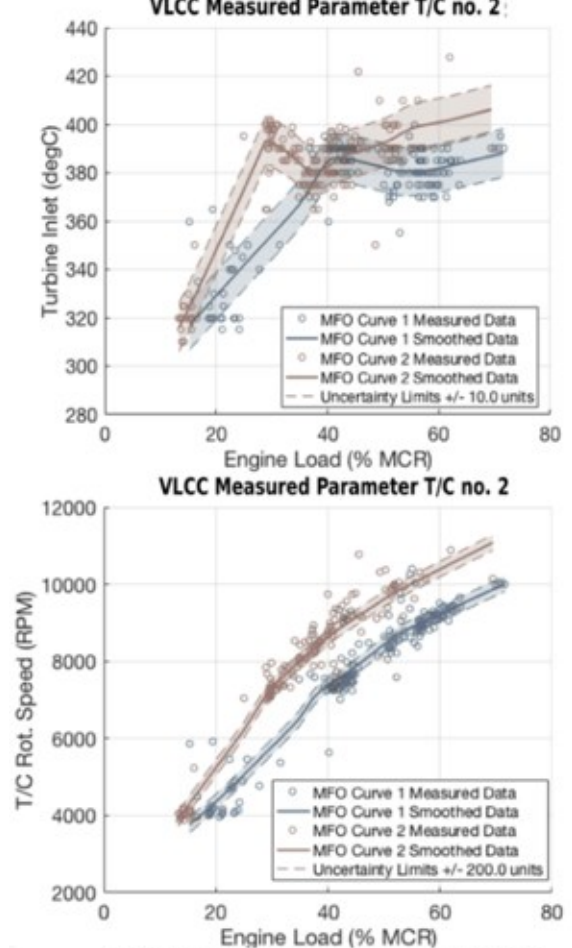

Container Ship Measured Parameter T/C no. 1
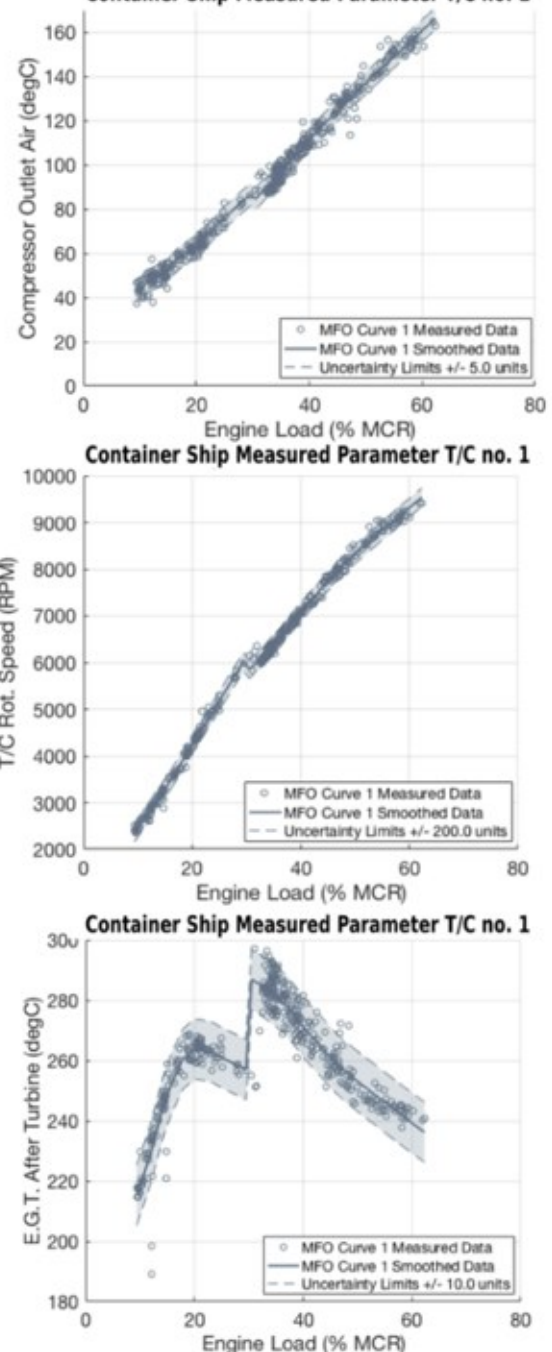

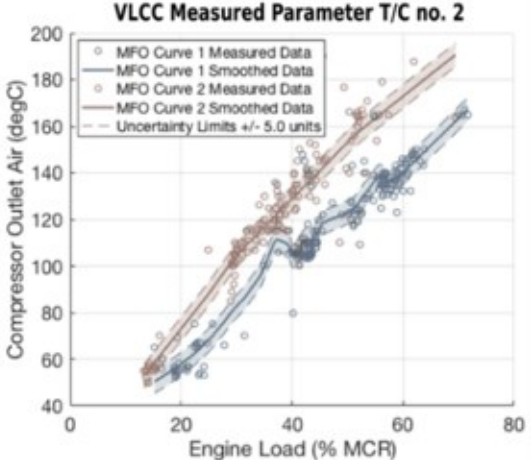

VLCC Measured Parameter
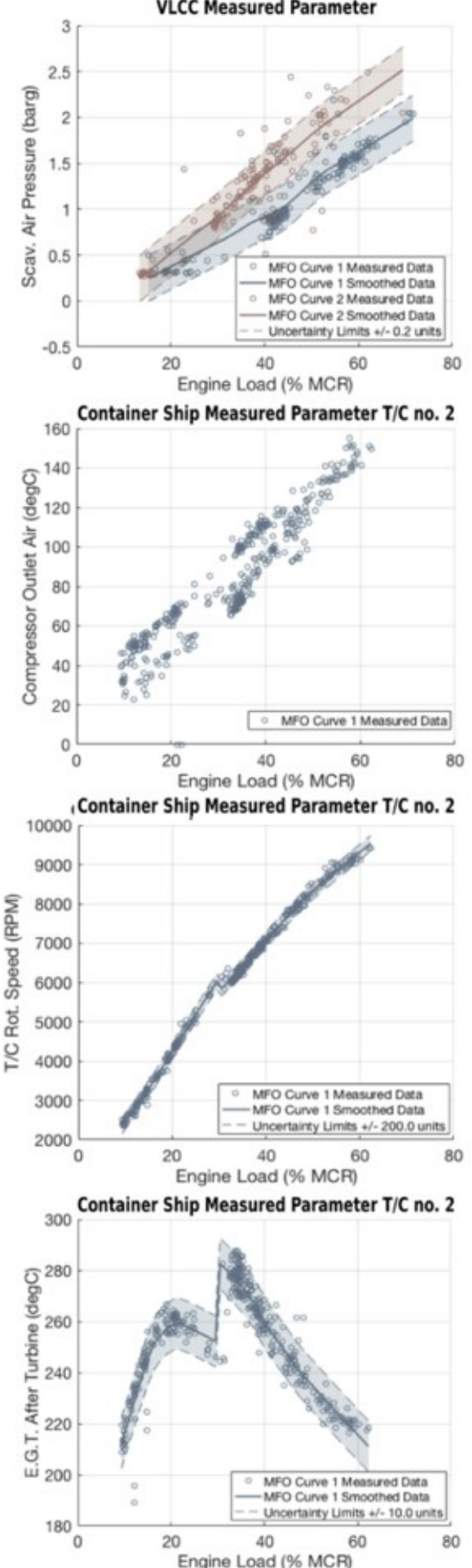

Figure 13: Plots of recorded RMPS with the largest MSE and percentage of points outside the certainty zone for the VLCC (top) and container ship (bottom) 


\subsection{Engine Air Flow Prediction}

The engine airflow is an essential parameter for the implementation of the proposed systematic methodology; hence, it is predicted for the case of the VLCC as all the required data is available, in specific, the compressor map, the $\mathrm{T} / \mathrm{C}$ shaft speed and the pressure ratio for both the engine turbochargers. It must be noted that change of the compressor map due to fouling was not considered in this study. Using the VLCC main engine shop trials as the baseline data for comparison, the compressor characteristic curves for both trial and operational conditions were derived and compared as illustrated in Fig. 14.

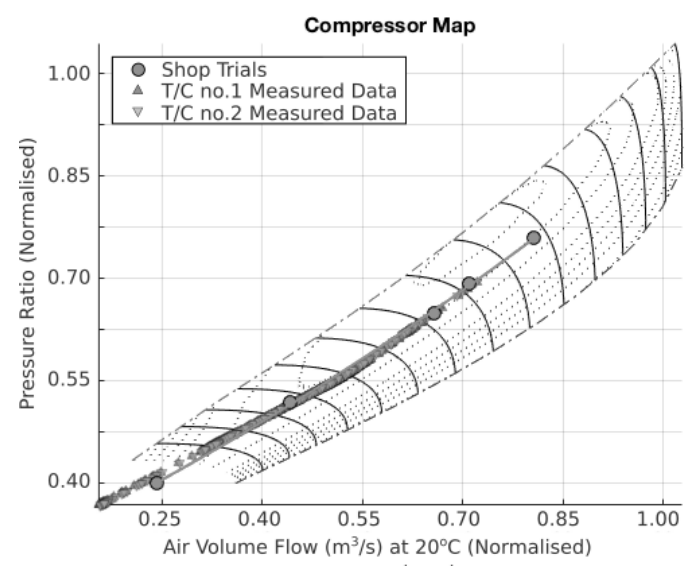

Figure 14: VLCC predicted airflow for both T/C compressors

It is inferred from Fig. 14 that both turbochargers compressors operate in a similar mode as their pressure ratio versus airflow data points almost overlap. This is expected as the pressure ratio and T/C shaft rotational speed data sets for each compressor almost coincide. The predicted compressor operating points exhibit very good agreement with the compressor operating points estimated from the engine shop trials. As expected for the operation of the turbocharger compressors of two-stroke diesel engines (Theotokatos \& Tzelepis, 2015), the compressor operating points lie in a single curve since the engine flow rate is a function of the engine cylinders pressure difference and effective flow area.

The percentage of points exceeding the compressor map maximum efficiency was calculated $55.2 \%$ for the T/C No. 2 and $61.3 \%$ for the T/C No. 2. In addition, the mean square error between predicted and measured efficiency was found to be $9.6 \%$ and $10.8 \%$ for the T/Cs No.1 and 2, respectively. The calculated compressor efficiency appears to exceed the compressor map maximum efficiency value in a large percentage of the data, which denotes inconsistencies or inaccuracies of the respective RMPs, mainly in the compressor outlet air temperature and, in a lesser extent, the T/C shaft speed and the pressure used for the calculation of the compressor temperature ratio and pressure ratio, respectively. The larger percentage value of this KPI for the case of the T/C No. 2 is also be related to the slightly largest dispersion observed in this $\mathrm{T} / \mathrm{C}$ compressor air outlet temperature ( $42.7 \%$ and $40.9 \%$ were the percentage of points outside the certainty zone for T/C No.1 and 2 compressor outlet temperature respectively as shown in Fig. 12).

\subsection{Energy \& Exergy Analyses}

To provide a basis for comparison, the baseline data parameters of the investigated VLCC propulsion engine corresponding to the engine operating region from $10 \%$ to $100 \%$ load were obtained by using the engine 
manufacturer web application (MAN Diesel \& Turbo, 2017) and used to calculate the respective parameters of the energy and exergy analyses. It must be noted that the manufacturer provides results for the engine operation in the propeller curve passing through the engine MCR point, the engine specific fuel consumption (which corresponds to the reciprocal of the engine efficiency) is given with a tolerance of 5\% (higher values were suggested for the low load region), and the exhaust gas temperature exiting the T/C turbine is provided with a tolerance of $10-15^{\circ} \mathrm{C}$. Therefore, greater uncertainty is expected for the results derived at the lower loads and the propeller curves that are not close to the propeller curve passing through the engine MCR point. The engine shop trials were also available and could be employed for the energy balance calculations; however, the derived results do not facilitate the comparison with the energy balance calculations in the MFO engine operating points as only measurements in a limited number of operating points were available (25\%, 50\%, 75\% and 100\% loads). On the above basis, it was decided to use the manufacturer data for the comparisons presented in this section.

The results of the energy analysis are presented in Table 7, based on which the following observations can be made. The engine almost retains its efficiency in the two MFO operating points with the grater load ( $42 \%$ and $46 \%$ loads) of the $1^{\text {st }}$ MFO propeller curve, although a slight engine efficiency reduction in the range 2-3.6 percentile points was estimated, which however lays within the tolerance of $5 \%$ provided by the engine manufacturer. For the other MFO operating points of the $1^{\text {st }}$ and the $2^{\text {nd }}$ MFO propeller curves a notable reduction of the engine efficiency in the range 8-9.7 percentile points was estimated. The greater engine efficiency reductions estimated for all the MFO points of the $2^{\text {nd }}$ MFO propeller curve are attributed to the fact that the $2^{\text {nd }}$ MFO propeller curve corresponds to the ship ballast sailing conditions and is further away from the propeller curve passing through the engine MCR point; as a result, the respective MFO operating points lie in regions of lower efficiency (Theotokatos \& Tzelepis, 2015). For all the examined MFO engine operating points, the derived engine efficiency reduction is associated with a corresponding increase of the exhaust gas energy flow ratio in comparison to the respective baseline data; increases in the range of 4-7 percentile points were estimated for the MFO operating points above $37 \%$ load whilst increases in the range of 20-23\% were derived for the lower load points (22\% and 14\% loads). These differences are attributed to (a) the usage of heavy fuel oil (ABS, 1984), (b) operating the engine at different engine speeds (in comparison with the baseline data), (c) the engine components degradation, and (d) the baseline data tolerance. The heavy fuel oil combustion takes place in a slower burning rate, which results in a lower cycle efficiency and a greater exhaust gas temperature at the end of the cylinders expansion process; thus, increasing the exhaust gas energy flow ratio. In addition, according to the prevailing correction practices, the engine efficiency is corrected to correspond to the ISO standard fuel and ambient conditions, however there is not correction procedure for the exhaust gas temperature based on the fuel quality. As the oceangoing vessels main engines mostly operate by using HFO, the energy analysis of the recorded PMPs operating data according to the methodology presented herein is quite useful tool for providing a more representative figure of the engine components operation under actual operating conditions.

The calculated jacket cooling water energy flow ratio for the case of the measured RMPs considerably reduced (by 3-4.5 percentile points for the MFO operating points with loads above 37\% and 9.6-11 percentile points for the MFO operating points with $22 \%$ and $14 \%$ loads). Similarly, the calculated lubricating oil energy flow ratio for the case of the measured RMPs is considerably reduced (4-4.5 percentile points for the MFO operating points with loads above $37 \%$; 6.6-8 percentile points for the MFO operating points with 22\% and 14\% loads). The above findings indicate that both the cooling water and lubricating oil systems operation (actual flow 
rates and temperatures) is considerably different from these systems respective baseline operation, which is expected in the engine design phase. Both systems are essential for the engine safe and reliable operation, therefore their appropriate monitoring and maintenance are important for the engine healthy function. However considering an energy management perspective, it can be inferred that these systems as well as heat recovery alternatives for these systems must be designed based on actual performance data instead of the expected (baseline) performance data, as in the latter case may result in an under-utilised non-optimal system design.

Table 7: Energy analysis results

\begin{tabular}{|c|c|c|c|c|c|c|}
\hline \multicolumn{7}{|c|}{$1^{\text {st }}$ MFO Propeller Curve } \\
\hline Engine load (\% MCR) & \multicolumn{2}{|c|}{22} & \multicolumn{2}{|c|}{42} & \multicolumn{2}{|c|}{56} \\
\hline Calculated Parameters & $\begin{array}{c}\text { From } \\
\text { Baseline }\end{array}$ & $\begin{array}{l}\text { From } \\
\text { RMPs }\end{array}$ & $\begin{array}{c}\text { From } \\
\text { Baseline }\end{array}$ & $\begin{array}{l}\text { From } \\
\text { RMPs }\end{array}$ & $\begin{array}{c}\text { From } \\
\text { Baseline }\end{array}$ & $\begin{array}{l}\text { From } \\
\text { RMPs }\end{array}$ \\
\hline Fuel Input Power (kW) & 13,896 & 15,376 & 25,608 & 25,021 & 33,212 & 33,145 \\
\hline Brake Efficiency (\%) & 51.3 & 42.5 & 51.9 & 50.0 & 53.7 & 50.1 \\
\hline $\begin{array}{c}\text { Exhaust Gas Energy } \\
\text { Flow Ratio (\%) } \\
\end{array}$ & 32.0 & 51.7 & 29.9 & 35.3 & 26.9 & 30.9 \\
\hline $\begin{array}{c}\text { Jacket Cooling Energy } \\
\text { Flow Ratio (\%) }\end{array}$ & 11.6 & 2.0 & 8.4 & 5.3 & 7.7 & 4.7 \\
\hline $\begin{array}{c}\text { L.O. Cooling Energy } \\
\text { Flow Ratio (\%) } \\
\end{array}$ & 9.6 & 1.6 & 7.1 & 1.9 & 6.2 & 1.7 \\
\hline $\begin{array}{c}\text { Scavenge Air Coolers } \\
\text { Energy Flow Ratio (\%) }\end{array}$ & 5.3 & 3.1 & 9.9 & 8.3 & 13.5 & 13.1 \\
\hline $\begin{array}{c}\text { Radiation Energy Flow } \\
\text { Ratio (\%) }\end{array}$ & 0.6 & 0.5 & 0.5 & 0.5 & 0.5 & 0.5 \\
\hline KPI $_{\text {Energy }}(\%)$ & -10.3 & -1.7 & -7.8 & -1.5 & -8.5 & -1.1 \\
\hline \multicolumn{7}{|c|}{$2^{\text {nd }}$ MFO Propeller Curve } \\
\hline$\%$ MCR & \multicolumn{2}{|c|}{14} & \multicolumn{2}{|c|}{37} & \multicolumn{2}{|c|}{50} \\
\hline Calculated Parameters & $\begin{array}{c}\text { From } \\
\text { Baseline }\end{array}$ & $\begin{array}{l}\text { From } \\
\text { RMPs }\end{array}$ & $\begin{array}{c}\text { From } \\
\text { Baseline }\end{array}$ & $\begin{array}{l}\text { From } \\
\text { RMPs }\end{array}$ & $\begin{array}{c}\text { From } \\
\text { Baseline }\end{array}$ & $\begin{array}{l}\text { From } \\
\text { RMPs }\end{array}$ \\
\hline Fuel Input Power (kW) & 9,293 & 13,250 & 22,806 & 25,977 & 29,757 & 33,802 \\
\hline Brake Efficiency (\%) & 40.8 & 32.1 & 51.3 & 42.0 & 52.7 & 44.5 \\
\hline $\begin{array}{c}\text { Exhaust Gas Energy } \\
\text { Flow Ratio (\%) }\end{array}$ & 31.6 & 59.2 & 30.9 & 37.6 & 28.0 & 33.4 \\
\hline $\begin{array}{c}\text { Jacket Cooling Energy } \\
\text { Flow Ratio (\%) }\end{array}$ & 14.8 & 3.6 & 8.9 & 4.4 & 8.0 & 4.1 \\
\hline $\begin{array}{l}\text { L.O. Cooling Energy } \\
\text { Flow Ratio (\%) }\end{array}$ & 11.3 & 4.7 & 7.6 & 2.9 & 6.6 & 2.5 \\
\hline $\begin{array}{c}\text { Scavenge Air Cooler } \\
\text { Energy Flow Ratio (\%) }\end{array}$ & 1.9 & 3.4 & 8.8 & 13.1 & 12.0 & 17.4 \\
\hline $\begin{array}{c}\text { Radiation Energy Flow } \\
\text { Ratio (\%) }\end{array}$ & 0.5 & 0.5 & 0.5 & 0.5 & 0.5 & 0.5 \\
\hline KPI $_{\text {Energy }}(\%)$ & -7.8 & -3.4 & -8.1 & -0.5 & -7.7 & -2.6 \\
\hline
\end{tabular}

The calculated scavenge air cooler energy flow ratio based on the measured RMPs sufficiently matches the respective results based on the baseline data for the MFO operating points at the two higher loads of the first MFO propeller curve (reductions of 1.6 and 0.4 percentile points were estimated). A greater reduction (2.2 percentile points) was derived for the lowest load MFO operating point of the first MFO propeller curve. For the second MFO propeller curve, increase of the SAC energy flow ratio in the range 1.5-5.4 percentile points were calculated by using the measured RMPs in comparison with the baseline data. The SAC energy flow is a function of the air flow rate (predicted herein), the compressor outlet temperature (that depends on the compressor efficiency and pressure ratio) and the SAC effectiveness (that depends on the SAC condition). It must also be noted that the baseline data correspond to the propeller curve passing through the engine MCR point, which partially justifies the observed deviations. From an energy management perspective, the calculated results indicate that the SAC energy flow is a considerable percentage of the total fuel energy; the results also point out the deviations from the 
baseline respective results. However, conclusions on the SAC energy quality cannot be drawn prior to examining the exergy analysis results.

The calculated energy analysis KPI values for the MFO engine operating points for the VLCC case are also shown in Table 7 and indicate that the energy balance error is smaller in the case of the measured data calculations compared to the calculations based on the baseline data for all operating points. This denotes that the performance of the overall energy analysis is satisfactory. In the case of the baseline data, the energy analysis KPI for the investigated MFO engine operating points (considering the propeller curve passing through the MCR point) was calculated to be in the range from $-7.7 \%$ to $-10.3 \%$, which denotes that the fuel power input is less than the sum of all heat flows and the engine brake power. In this respect, it appears that the use of the manufacturer data results in an underestimation of the engine fuel consumption, thus overestimating the engine efficiency. However, when considering the manufacturer tolerances for the engine specific fuel consumption and the exhaust gas temperature exiting the engine (both being in the range from 5\% to 15\% (MAN Diesel \& Turbo, 2017)), the absolute energy KPI values become close to 0 . Notwithstanding the above, these tolerances were not considered for the calculations presented in this study. Based on the preceding analysis, it can be inferred that the energy analysis does provide insight into the engine actual operation, however the energy analysis results need to be meticulously examined.

The derived exergy analysis results including the exergy flows ratios and the exergy destruction shares in the various engine components for the MFO engine operating points and their comparison with the corresponding baseline data are presented in Table 8 and Fig. 15. The exergy analysis can provide a better insight to the source of inefficiencies. From these results, it can be inferred that the largest exergy flow leaving the engine control volume is associated with the exhaust gas. The other exergy flows account for less than $1.6 \%$ of the total fuel exergy input, excluding the shaft power. The exhaust gas, due to its high temperature in comparison to the ambient, contains energy of high quality, which justifies the installation of exhaust gas waste heat recovery systems that use an exhaust gas boiler to produce either saturated steam or both saturated and superheated steam; in the latter case, the superheated steam is used for electric energy generation. The jacket cooling water exergy outflow also amounts to approximately $30-60 \%$ of the exergy flow of the exhaust gas depending on the operating point of the engine, which denotes that there is high quality energy being wasted from the engine cooling system that can potentially be recovered. This is not observed in the baseline case where the jacket cooling water exergy outflow is much lower, thus indicating that the engine parameters are well-adjusted and the engine operates without significant degradation of its components, as expected for a new engine. However, as it was also commented in the preceding paragraphs of the energy analysis discussion, the actual operation of the engine cooling systems (water and lubricating oil) substantially differentiates than the expected one in the design phase. The SAC exergy flow (incorporated in the sum of other exergy flow ratios) is very low, due to the low temperature of the SAC cooling water. In this respect, systems for recovering the SAC cooling water energy are not expected to result in substantial benefits unless the system utilises directly the high temperature air exiting the compressor.

Considering the results for the exergy destruction share of the engine main components presented in Table 8 and Fig. 15, it is inferred that less exergy amount is destroyed in the baseline case in comparison to the actual engine operation, which is attributed to the degradation of the engine and its components. The engine block is responsible for the greatest share of exergy destruction; on this basis, measures to obtain a better understanding 
on the involved processes and phenomena resulting in irreversibility include the closer monitoring or/and the more detailed modelling of the engine cylinders block. However, it must be noted that for the engine block case, most of the exergy destroyed is related to the combustion process; thus, for pursuing significant improvements, optimisation of the engine settings to improve cycle efficiency needs to be considered. The following engine components follow in the exergy destruction share: the turbocharger compressor, the T/C turbine, and the scavenge air cooler. For the case of the $2^{\text {nd }}$ MFO propeller curve, the exergy destroyed in the compressor for the actual engine operation is considerably greater that the baseline one. This indicates that measures such as regular maintenance and compressor cleaning/washing can be implemented in order to decrease the compressor destroyed exergy thus improving its performance.

Table 8: Exergy analysis results

\begin{tabular}{|c|c|c|c|c|c|c|}
\hline \multicolumn{7}{|c|}{$1^{\text {st }}$ MFO Propeller Curve } \\
\hline Engine load (\% MCR) & \multicolumn{2}{|c|}{22} & \multicolumn{2}{|c|}{42} & \multicolumn{2}{|c|}{56} \\
\hline Calculated parameters & $\begin{array}{c}\text { From } \\
\text { Baseline }\end{array}$ & From RMPs & $\begin{array}{c}\text { From } \\
\text { Baseline }\end{array}$ & $\begin{array}{l}\text { From } \\
\text { RMPs }\end{array}$ & $\begin{array}{c}\text { From } \\
\text { Baseline }\end{array}$ & $\begin{array}{l}\text { From } \\
\text { RMPs }\end{array}$ \\
\hline Fuel Exergy Inflow (kW) & 14,838 & 16,418 & 27,344 & 26,711 & 35,463 & 35,392 \\
\hline Shaft Exergy ratio (\%) & 48.5 & 40.7 & 48.9 & 41.6 & 50.4 & 43.2 \\
\hline $\begin{array}{c}\text { Exhaust Gas Exergy Flow } \\
\text { Ratio (\%) }\end{array}$ & 6.7 & 13.3 & 6.9 & 8.1 & 5.9 & 6.6 \\
\hline $\begin{array}{c}\text { Jacket Cooling Water } \\
\text { Exergy Flow Ratio (\%) } \\
\end{array}$ & 0.9 & 7.4 & 0.7 & 4.1 & 0.6 & 3.1 \\
\hline $\begin{array}{c}\text { Compressors Exergy } \\
\text { Destruction Share }(\%)\end{array}$ & 5.3 & 3.6 & 8.0 & 6.9 & 10.8 & 10.7 \\
\hline $\begin{array}{c}\text { Scavenge Air Cooling } \\
\text { Exergy Destruction Share } \\
(\%)\end{array}$ & 0.2 & 0.1 & 0.5 & 0.6 & 0.7 & 1.4 \\
\hline $\begin{array}{c}\text { Engine Block Exergy } \\
\text { Destruction Share (\%) }\end{array}$ & 33.3 & 36.1 & 26.7 & 34.5 & 22.0 & 26.2 \\
\hline $\begin{array}{c}\text { Turbines Exergy } \\
\text { Destruction Share (\%) }\end{array}$ & 4.6 & 3.4 & 6.2 & 4.9 & 8.2 & 7.9 \\
\hline $\begin{array}{c}\text { Sum of other exergy flows } \\
\text { ratios }(\%)\end{array}$ & 0.4 & 1.6 & 0.7 & 0.9 & 1.2 & 1.0 \\
\hline KPIExergy $(\%)$ & -0.03 & -6.3 & 1.8 & -1.4 & 1.6 & 0.01 \\
\hline \multicolumn{7}{|c|}{$2^{\text {nd }}$ MFO Propeller Curve } \\
\hline Engine load (\% MCR) & \multicolumn{2}{|c|}{14} & \multicolumn{2}{|c|}{37} & \multicolumn{2}{|c|}{$\mathbf{5 0}$} \\
\hline Calculated Parameters & $\begin{array}{c}\text { From } \\
\text { Baseline }\end{array}$ & From RMPs & $\begin{array}{c}\text { From } \\
\text { Baseline }\end{array}$ & $\begin{array}{l}\text { From } \\
\text { RMPs }\end{array}$ & $\begin{array}{c}\text { From } \\
\text { Baseline }\end{array}$ & $\begin{array}{l}\text { From } \\
\text { RMPs }\end{array}$ \\
\hline Fuel Exergy Inflow (kW) & 9,923 & 14,148 & 24,352 & 27,738 & 31,774 & 36,093 \\
\hline $\begin{array}{c}\text { Shaft Exergy Flow Ratio } \\
(\%)\end{array}$ & 44.9 & 37.9 & 48.5 & 41.2 & 49.6 & 43.4 \\
\hline $\begin{array}{c}\text { Exhaust Gas Exergy Flow } \\
\text { Ratio (\%) }\end{array}$ & 6.1 & 18.7 & 7.5 & 9.5 & 6.3 & 7.8 \\
\hline $\begin{array}{c}\text { Jacket Cooling Water } \\
\text { Exergy Flow }\end{array}$ & 1.2 & 10.9 & 0.7 & 4.5 & 0.6 & 3.5 \\
\hline $\begin{array}{c}\text { Compressors Exergy } \\
\text { Destruction Share (\%) }\end{array}$ & 2.6 & 5.2 & 7.5 & 12.5 & 9.7 & 16.1 \\
\hline $\begin{array}{c}\text { Scavenge Air Coolers } \\
\text { Exergy Destruction Share } \\
(\%)\end{array}$ & 0.1 & 0.1 & 0.5 & 1.5 & 0.6 & 2.4 \\
\hline $\begin{array}{c}\text { Engine Block Exergy } \\
\text { Destruction Share (\%) }\end{array}$ & 41.5 & 27.5 & 27.7 & 20.4 & 23.8 & 14.0 \\
\hline $\begin{array}{c}\text { Engine Turbines Exergy } \\
\text { Destruction Share }(\%)\end{array}$ & 2.5 & 4.7 & 5.7 & 9.3 & 7.4 & 11.7 \\
\hline $\begin{array}{c}\text { Sum of other }{ }^{*} \text { exergy flows } \\
\text { ratios }(\%)\end{array}$ & 0.4 & 1.5 & 0.6 & 1.0 & 1.0 & 1.0 \\
\hline $\begin{array}{c}\text { KPIExergy }(\%) \\
\end{array}$ & 0.8 & -6.5 & 1.9 & 0.3 & 1.9 & 0.2 \\
\hline
\end{tabular}

${ }^{*}$ Other include the lubricating oil exergy outflow, the SAC cooling water exergy outflow and the radiation exergy flow. 

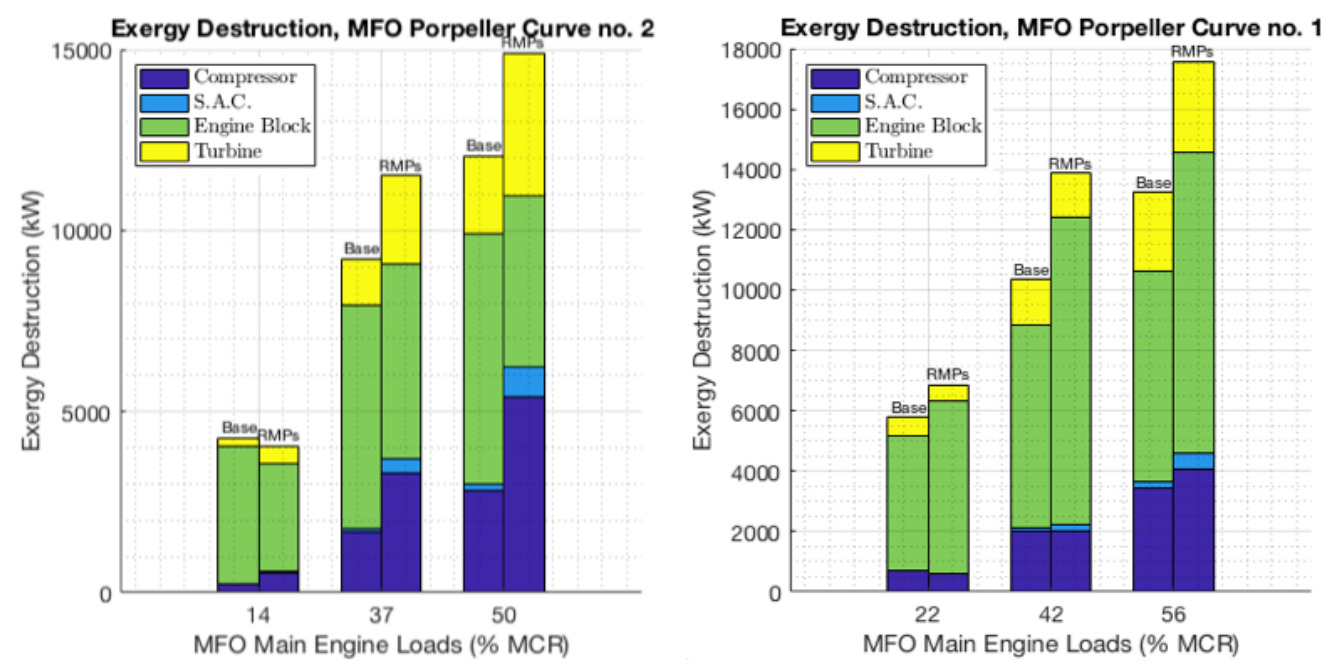

Figure 15: Exergy destruction in the engine components

The maximum potential for the exergy destruction reduction is estimated based on the differences between the actual and baseline figures shown in Fig. 15. The baseline calculations correspond to the best engine condition (new engine) and thus set the target to be achieved by readjusting the engine settings or performing maintenance tasks (cleaning, repairing or replacing engine components) throughout the engine lifetime. In the case of a new engine, the exergy destruction is attributed purely to the engine design and thus it is referred as intrinsic or unavoidable (Kotas, 1985). On the contrary, the exergy destruction is characterised as avoidable and improvements can be sought to reduce the destroyed exergy in the following cases: (a) the engine suffers from degradation or fouling of its components, (b) deviation from the optimally adjusted engine settings takes place, (c) the engine operates with fuels of bad quality, and (d) the engine operating point corresponds to low efficiency.

The exergy analysis KPI values were found to be in the range of $-0.03 \%$ to $1.9 \%$ for the baseline data, whereas values in the region -6.5 to 0.22 were calculated for the measured RMPs (the lower values correspond to the calculations of the MFO operating points with the lower loads). These numbers demonstrate the consistency of the carried out analysis, as well as the whole methodology proposed in this study, as the precious phases provided the input for in implementation of the energy/exergy analyses.

In conclusion, from the preceding discussion, it is verified that the exergy analysis provided additional insight on the engine components condition and the energy flows quality and therefore, it is considered as an important stage of the developed methodology.

\subsection{Energy Saving Initiatives}

Based on the results and discussion presented in the preceding section, the following energy saving initiatives are proposed for the investigated VLCC vessel.

- Acquisition of RMPs by using an automated monitoring system with variable sampling rate for capturing both the engine steady state and transient periods.

- Analysis of the acquired data according to the methodology proposed in this study to obtain the better understanding on the actual operation of the ship propulsion system and its components.

- Identification of the components with considerable deviations from the baseline conditions with regard to the energy losses and exergy losses and their closer monitoring. 
- Monitor and readjust the engine settings to provide the maximum engine efficiency.

- Perform maintenance tasks based on the results of the energy and exergy analysis including cleaning, repairing and replacing underperforming engine components.

- Retrofitting of WHR system for recovering the exhaust gas and scavenge air cooling water wasted heat; the system should be designed to match the engine operating profile as estimated with the proposed methodology of this study.

- Model the engine by using a detailed approach (first principles) to obtain a better understanding on the engine behaviour and evaluate the required actions to improve the engine performance.

- Enhancing crew awareness by taking initiatives on informing the crew and ship operator for deviations from the baseline data.

- Develop a decision support system based on the proposed method herein to rank alternative actions for the propulsion system energy efficiency improvement.

\section{CONCLUSIONS}

In this work, a systematic methodology for the ship propulsion engine energy monitoring was developed and tested using data from three case study vessels covering a broad range of data recording methods. The methodology integrates a number of methods to analyse the recorded data including statistical analysis to derive the MFO propeller curves and the MFO operating points as well as to quantify the quality of measured data, performing energy and exergy analyses and identifying appropriate energy saving initiatives.

The main findings of this work are as follows:

- The methodology was fully implemented for the VLCC, and partially implemented for other two ships (containership and bulk carrier) up to the data analysis phase; it was therefore demonstrated that the methodology can be applied to a wide spectrum of oceangoing ship types.

- The systematic methodology is capable of providing consistent results as it is deduced from the adequate estimation of the MFO propeller curves as well as the energy and exergy analyses KPIs despite the questionable quality of the used data (from the vessel noon reports).

- The results analysis showed that for all of the investigated ships, slow steaming was used with their most frequently occurring main engine loads ranging from a minimum of $24 \%$ to $56 \%$ of the MCR.

- The data quality assessment KPIs indicated that the data recorded with ADLM systems (for the cases of the container ship and bulk carrier) exhibited a significantly improved quality in comparison with the VLCC manually recorded data (noon report). This emphasises the need to use ADLM systems in order to obtain reliable data and subsequently conducting consistent energy monitoring, which is needed for developing an effective energy management strategy.

- Considering the measurements accuracy/uncertainty, the proposed statistical analysis of the acquired data supplemented by the engine air flow prediction is requisite for reliably estimating the input parameters and the successful implementation of the energy and exergy analyses phase. Using raw data as a direct input to energy and exergy analysis calculations may result in considerable errors and inconsistent results. 
- The energy analysis KPI for the VLCC measured data was calculated to be in the range $-3.6 \%$ to $-0.5 \%$, whereas the respective results for the baseline data were in the range -7.7 to $-10.3 \%$. This relatively small percentage error proves the consistency of the energy analysis calculations for the measured RMPs, the employed air flow modelling and the considered assumptions for estimating the missing RMPS. However, further improvements must be sought in the ADLM systems components (hardware and software) for improving the reliability and accuracy of the acquired data, as an effective energy management typically considers savings in the order of $0.5 \%$ to $2 \%$ (Bal Beşikçi, et al., 2016).

- The energy analysis results revealed that the actual operation of the engine cooling systems considerably deviates for the one expected in the design phase. In this respect, the design of the engine cooling systems must be designed based on actual performance data instead of the expected performance data, as in the latter case may result in an under-utilised non-optimal system design.

- The exergy analysis indicated that the actual exhaust gas exergy flow ratio is greater than what expected from the baseline data pinpointing the engine actual operation differences. The exhaust gas and the jacket cooling water energy flows were identified as considerable allowing for potential energy saving initiatives employing heat recovery systems. On the contrary, the SAC exergy flow was found to be very low, rendering initiatives to install systems for recovering the SAC cooling water energy unfeasible unless the system utilises directly the high temperature air exiting the compressor.

- For the VLCC propulsion system, the exergy analysis indicated a number of components with either considerable deviation from the baseline case or significant energy destruction, in specific the engine block, the compressor and the turbine. This means that close monitoring of these components is required for identifying large deviations and implement mitigating measures, which include the readjustment of the engine settings and maintenance tasks such as cleaning, repairing or replacing engine components.

- Based on the proposed methodology, the most appropriate energy saving initiatives can be identified and pursued.

In summary, based on the derived results and the comparison between the three investigated cases, a better understanding for the ship operational practices are obtained, the recorded data quality is quantified and the engine components with considerable performance variation from the baseline as well as components with large exergy destruction are identified. It is inferred that the method provides consistent results, whilst emphasising the benefits from better data collection practices in the maritime industry. It is expected that the proposed methodology herein will become a valuable tool for the energy management of ship propulsion systems and future work should focus on the development of a decision support system for the propulsion system energy efficiency improvement.

\section{ACKNOWLEDGMENTS}

DNV GL and RCCL support is greatly acknowledged by the corresponding author. 


\section{Abbreviations}

ADLM: Automatic Data Logging Monitoring CEAS: Computerised Engine Application System

$\mathrm{CO}_{2}$ : Carbon Dioxide

EEOI: Energy Efficiency Operational Indicator

E/R: Engine Room

FW: Fresh Water

IMO: International Maritime Organisation

KDE: Kernel Density Estimator

LHV: Lower Heating Value

$\mathrm{M} / \mathrm{E}$ : Main Engine

MCR: Maximum Continuous Rating

HFO: Heavy Fuel Oil

MDO: Marine Diesel Oil

\section{Nomenclature List}

Symbols

c: Constant

$c_{p}$ : Specific heat capacity at constant pressure

$(\mathrm{J} / \mathrm{kg} / \mathrm{K})$

$e$ : Propeller curve equation exponent (-)

EX: Exergy flow (W)

$h$ : Bandwidth (-) or specific enthalpy $(\mathrm{J} / \mathrm{kg})$

$\dot{I}$ : Rate of exergy destruction (W)

$L H V$ : Lower heating value of fuel $(\mathrm{J} / \mathrm{kg})$

$\dot{m}$ : Mass flow rate $(\mathrm{kg} / \mathrm{s})$

$P$ : Power (W)

$p$ : Pressure $(\mathrm{Pa})$

pr: Pressure ratio (-)

$N$ : Rotational speed (r/min)

$\dot{Q}$ : Heat flow (W)

$T$ : Temperature (K)

\section{Subscripts}

amb: Ambient

$C$ : Turbocharger compressor

Cor: Corrected value of the parameter

$C W$ : Scavenge air cooler cooling water

$E B$ : Engine Block

$D$ : distance propeller curve parameter

$E$ : Engine

Exh: Turbocharger turbine outlet

filt: Engine air filter

$h i$ : Upper limit of evaluation

$I$ : Integral propeller curve parameter

ISO: ISO value

JCW : Jacket cooling water
MFO: Most Frequently Occurring

MRV: Monitoring, Reporting and Verification

NOx: Nitrogen Oxides

PDF: Probability Density Function

RLOWESS: Robust Local-Weighted Scatterplot

Smoothing

RMP: Required Monitored Parameter

SAC: Scavenge Air Cooler

SEEMP: Ship Energy Efficiency Management Plan

SFOC: Specific Fuel Oil Consumption

SOx: Sulphur Oxides

T/C: Turbocharger

VLCC: Very Large Crude Carrier

V: Total number of voyages (-)

Greek Symbols:

$\alpha$ : Propeller curve equation coefficient

$\gamma$ : Ratio of specific heats (-)

$\Delta$ : Difference

$\eta$ : Efficiency (-)

$\mu$ : Mean (-)

$\rho:$ Density $\left(\mathrm{kg} / \mathrm{m}^{3}\right)$

$\sigma:$ Standard deviation

$\phi$ : Energy flow ratio (-)

$\chi$ : Exergy destruction share (-)

$\psi$ : Exergy loss ratio (-)
$L M$ : Logarithmic mean temperature

$L O$ : lubricating oil

lo: Lower limit of evaluation

MCR: Maximum continuous rating

$M / E$ : Main Engine

Rad: Radiation

$T / C$ : Turbocharger

$T$ : Turbocharger turbine

$S A C$ : Scavenge air cooler

scav: Scavenge air

user: User defined input

$\mathrm{V}$ : Total number of voyages

$v$ : Number of voyages of a most frequently

occurring propeller curve

Operators and Functions

$\operatorname{argmin}(f(x))$ : The abscissa of $x$ where $f(x)$ is minimum $\operatorname{argmax}(f(x))$ : The abscissa of $x$ where $f(x)$ is maximum $\hat{f}_{h}(\mathbf{X})$ : Gaussian Kernel Density function of bandwidth $h$ of a random variable $\mathbf{X}$ $\mathrm{IQR}(\mathbf{X})$ : Interquartile range of a random variable $\mathbf{X}$ mean $(\vec{x})$ : Mean of a vector $\vec{x}$ $\bar{x}$ : mean of a variable $x$ $\operatorname{std}(\vec{x}):$ Standard deviation of a vector $\vec{x}$ 


\section{References}

Abadie, L. M., Goicoechea, N. \& Galarraga, I., 2017. Adapting the shipping sector to stricter emissions regulations: Fuel switching or installing a scrubber?. Transporation Research Part D, Volume 57, pp. 237-250.

ABS, 1984. Notes on Heavy Fuel Oil. Houston, TX: American Bureau of Shipping.

Adland, R., Cariou, P., Jia, H. \& Wolff, F.-C., 2018. The energy efficiency effects of periodic ship hull cleaning. Journal of Cleaner Production, Volume 178, pp. 1-13.

Aldous, L., Smith, T., Bucknall, R. \& Thompson, P., 2015. Uncertainty analysis in ship performance monitoring. Ocean Engineering, Part B, Volume 110, pp. 29-38.

Armstrong, V. N. \& Banks, C., 2015. Integrated approach to vessel energy efficiency.. Ocean Engineering Part $B$, Volume 110 , pp. 39-48.

Bal Beşikçi, E., Kececi, T., Arslan, O. \& Turan, O., 2016. An application of fuzzy-AHP to ship operational energy efficiency measures. Ocean Engineering, Jan., Volume 121, pp. 392-402.

Baldi, F. et al., 2016. Optimal load allocation of complex ship power plants. Energy Conversion \& Management, Volume 124, pp. 344-356.

Baldi, F., Johnson, H., Gabrielii, C. \& Andersson, K., 2015. Energy and exergy analysis of ship energy systems - The case study of a chemical tanker. International Journal of Thermodynamics, 18(2), pp. 82-93.

BEIS, 2016. Calorific Values of Fuels. [Online]

Available at: https://www.gov.uk/government/collections/oil-statistics

[Accessed 236 2018].

Blanco-Davis, E. \& Zhou, P., 2016. Life Cycle Assessment as a complementary utility to regulatory measures of shipping energy efficiency. Ocean Engineering, Volume 128, pp. 94-104.

Brynolf, S., Fridell, E. \& Andersson, K., 2014. Environmental assessment of marine fuels: liquefied natural gas, liquefied biogas, methanol and bio-methanol. Journal of Cleaner Production, Volume 74, pp. 86-95.

Carlton, J. S., 2007. Marine Propellers and Propulsion, 2nd Ed. In: Oxford: Butterworth-Heinemann.

Chi, H. et al., 2018. A framework for real-time monitoring of energy efficiency of marine vessels. Energy, Volume 145, pp. 246-260.

Cichowicz, J., Theotokatos, G. \& Vassalos, D., 2015. Dynamic energy modelling for ship life-cycle performance assessment. Ocean Engineering, 110(Part B), pp. 49-61.

Coraddu, A. et al., 2016. Vessels fuel consumption forecast and trim optimisation: a data analytics perspective. Ocean Engineering, Volume 130, pp. 351-370.

Deligiannis, P., 2017. Ship performance indicator. Marine Policy, Volume 75, pp. 204-209.

Deniz, C. \& Zincir, B., 2016. Environmental and economical assessment of marine fuels. Journal of Cleaner Production, Volume 113, pp. 438-449.

Dimopoulos, G., Georgopoulou, C. \& Kakalis, N., 2012. The introduction of exergy analysis to the thermoeconomic modelling and optimisation of a marine combined cycle system. Perugia, Italy, Proceedings of the 25 th international conference on efficiency, cost, optimisation, simulation and environmental impact of energy systems (ECOS), 26-29 June 2012.

Dimopoulos, G. G. et al., 2014. A general-purpose process modelling framework for marine energy systems. Energy Conversion and Management, Volume 86, pp. 325-339.

Dimopoulos, G. G. \& Kakalis, N. M., 2014. Next Generation Energy Management; DNV-GL Strategic Research \& Innovation Position Paper 5-2014.

Dörr, M., Wahren, S. \& Bauernhansl, T., 2013. Methodology for Energy Efficiency on Process Level. In Procedia CIRP, Volume 7, pp. 652-657.

Duarte, B., Saraiva, P. \& Pantelides, C., 2004. Combined Mechanistic and Empirical Modelling. International Journal of Chemical Reactor Engineering, 2(1).

Du, K. L. \& Swamy, M. N. S., 2014. Neural Networks \& Statistical Learning. s.1.:Springer. 
EC, 2013. Regulation of the European Parliament and of the Council on the monitoring, reporting and verification of carbon dioxide emissions from maritime transport and amending Regulation. COM(2013) 480 final.. European Commission, Brussels 28/6/2013: s.n.

Eriksson, L. \& Nielsen, L., 2014. Turbocharging Basics and Models. In: Modeling and control of engines and drivelines. s.1.:John Wiley and Sons Ltd, pp. 211-261.

Francesco Di, M. \& Lazagni, M., 2017. On line measurement of the lower heating value of waste and energetic efficiency of an existing plant to energy plant: Identification of uncertainty associated to probes and their influence on the results. Energy Procedia, Volume 126, pp. 613-620.

Galli, A. M., Gualeni, P. \& Stranieri, G., 2014. Monitoring and analysis of the performance data of a RO-PAX ship in the perspective of energy efficiency. Polish Maritime Research, Volume 21, pp. 18-26.

GMI, 2017. Marine Diesel Engine Market Share-Industry Size Report 2024, s.1.: Global Market Insights, May 2017; Report ID: GMI158.

Gramacki, A., 2018. Nonparametric Kernel Density Estimation and Its Computational Aspects. s.1.:Springer International Publishing AG.

Guan, C., Theotokatos, G., Zhou, P. \& Chen, H., 2014. Computational investigation of a large containership propulsion engine operation at slow steaming conditions.. Applied Energy, Volume 130, pp. 370 - 383.

Heer, B. \& Maussner, A., 2005. Dynamic General Equilibrium Modelling: Computational Methods and Applicationsi. Heidelberg: Springer Berlin.

IAPWS, 2007. Revised Release on the IAPWS Industrial Formulation 1997 for the Thermodynamic Properties of Water and Steam. Lucerne: The International Association for the Properties of Water and Steam.

IMO, 2012. Annex 9, Resolution MEPC 213(63). 2012 Guidelines for the development of a ship energy efficiency management plan (SEEMP). s.1.:s.n.

IMO, 2014. Annex 5, Resolution MEPC.245(66). Guidelines on the Method of Calculation of the Attained Energy Efficiency Design Index (EEDI). s.l.:s.n.

IMO, 2015. Third IMO GHG Study 2014, London: International Maritime Organisation.

ISO 3016-1:2002, 2002. Reciprocating Internal Combustion Engines. Part 1: Declarations of power, fuel and lubricating oil consumptions, and test methods - Additional requirements for engines for general use. s.1.:s.n.

Jafarzadeh, S. \& Utne, I. B., 2014. A framework to bridge the energy efficiency gap in shipping. Energy, Volume 69, pp. 603-612.

Jensen, et al., 2018. Energy-efficient operational training in a ship bridge simulator. Journal of Cleaner Production, Volume 171, pp. 175-183.

Jeong, B., Wang, H., Oguz, E. \& Zhou, P., 2018. An effective framework for life cycle and cost assessment for marine vessels aiming to select optimal propulsion systems. Journal of Cleaner Production, Volume 187, pp. 111-130.

Johnson, H., Johansson, M., Andersson, K. \& Södahl, B., 2013. Will the ship energy efficiency management plan reduce CO2 emissions? A comparison with ISO 50001 and the ISM code. Maritime Policy \& Management, 40(2), pp. 177-190.

Johnson, H. \& Styhre, L., 2015. Increased energy efficiency in short sea shipping through decreased time in port. Transportation Research Part A: Policy and Practice, Volume 71, pp. 167-178.

Kanneganti, H. et al., 2017. Specification of energy assessment methodologies to satisfy ISO 50001 energy management standard. Sustainable Energy Technologies and Assessments, Volume 23, pp. 121-135.

Kaushik, S. C. \& Singh, O. K., 2013. Estimation of chemical exergy of solid, liquid and gaseous fuels used in thermal power plants. Journal of Thermal Analysis and Calorimetry.

Kotas, T. J., 1985. The Exergy Method of Thermal Plant Analysis. Boston: Butterworths.

Lajic, Z., Blanke, M. \& Nielsen, U. D., 2009. Fault Detection for Shipboard Monitoring - Volterra Kernel and Hammerstein Model Approaches. IFAC Proceedings Volumes, 42(8), pp. 24-29.

Livanos, G., Theotokatos, G. \& Kyrtatos, N., 2003. Simulation of large marine two-stroke diesel engine operation during fire in the scavenging air receiver. Journal of Marine Engineering \& Technology, 2(2), pp. 916. 
Llamas, X. \& Eriksson, L., 2015. Parameterizing Compact and Extensible Compressor Models Using Orthogonal Distance Minimization. J. Eng. Gas Turbines Power , 139(1).

Llamas, X. \& Eriksson, L., 2018. LiU CPgui: A Toolbox for Parameterizing Compressor Models, Linoping, Sweden: Vehicular Systems, Department of Electrical Engineering Linkoping University.

Logan, K. P., 2011. Using a Ship’s Propeller for Hull Condition Monitoring. Philadelphia, USA, ASNE Intelligent Ship Symposium IX.

Lützen, M., Lindegaard Mikkelsen, L., Jensen, S. \& Rasmussen, H. B., 2017. Energy efficiency of working vessels - A framework. Journal of Cleaner Production, Volume 143, pp. 90-99.

MAN B\&W, 2007. Instructions: Hyundai-MAN B\&W Diesel Engines Operation. s.1.:Hyundai Heavy Industries Co. Ltd., Engine \& Machinery Division.

MAN Diesel \& Turbo, 2010. MAN B\&W S90MC-C8-TII Project Guide. Copenhagen: s.n.

MAN Diesel \& Turbo, 2011. Basic Principles of Ship Propulsion. Copenhagen, Denmark: 5510-0004-02ppr, Dec. 2011.

MAN Diesel \& Turbo, 2014. Waste Heat Recovery System (WHRS) for Reduction of Fuel Consumption, Emissions and EEDI. Copenhagen, Denmark: 5510-0136-00ppr, Aug 2012.

MAN Diesel \& Turbo, 2017. Computerised Engine Application System Calculations. [Online] Available at: http://marine.man.eu/two-stroke/ceas

Marty, P., 2014. Etude de l'efficacite energetique des navires: developpement et application d'une methode d'analyse. s.1.:Ecole Centrale de Nantes (ECN), $\mathrm{PhD}$. Thesis.

Marty, P., Hétet, J.-F., Chalet, D. \& Corrignan, P., 2016. Exergy Analysis of Complex Ship Energy Systems. MDPI Entropy, 8 April, 18(4), pp. 1-18.

Meng, Q., Du, Y. \& Wang, Y., 2016. Shipping log data based container ship fuel efficiency modeling. Transportation Research Part B: Methodological, Volume 83, pp. 207-229.

Mizythras, P., Boulougouris, E. \& Theotokatos, G., 2018. Numerical study of propulsion system performance during ship acceleration. Ocean Engineering, Volume 149, p. 383-396.

Nielsen, U. D., Lajic, Z. \& Jensen, J. J., 2012. Towards fault-tolerant decision support systems for ship operator guidance. Reliability Engineering \& System Safety, Volume 104, pp. 1-14.

Nunes, R., Alvim-Ferraz, M., Martins, F. \& Sousa, S., 2017. The activity-based methodology to assess ship emissions - A review. Environmental Pollution, Volume 231, pp. 87-103.

Perera, L. P. \& Mo, B., 2016. Data analysis on marine engine operating regions in relation to ship navigation. Ocean Engineering, Volume 128, pp. 163-172.

Perera, L. P. \& Mo, B., 2017. Marine Engine-Centered Data Analytics for Ship Performance Monitoring. Journal of Offshore Mechanics and Arctic Engineering, April.Volume 139.

Petersen, J. P., Jacobsen, D. J. \& Winther, O., 2012. Statistical modelling for ship propulsion efficiency. Journal of marine science and technology, 17(1), pp. 30-39.

Poulsen, R. T. \& Johnson, H., 2016. The logic of business vs. the logic of energy management practice: understanding the choices and effects of energy consumption monitoring systems in shipping companies. Journal of Cleaner Production, Volume 112, pp. 3785-3797.

Rehmatulla, N. \& Smith, T., 2015. , Barriers to energy efficient and low carbon shipping. Ocean Engineering Part B, Volume 110, pp. 102-112.

SAE J1826, 1995. Turbocharger Gas Stand Test Code, s.1.: SAE Standard.

Sheather, S. J., 2004. Density Estimation. Institute of Mathematical Statistics: Statistical Science, 19(4), pp. 588-597.

Siegmund, B., 1999. Data analysis: statistical and computational methods for scientists and engineers. 3 ed. New York: Springer.

Stewart, S. W. \& Shelton, S. V., 2004. The Usefulness of Entropic Average Temperatures. Anaheim, California, s.n., pp. 151-155. 
Theotokatos, G. \& Tzelepis, V., 2015. A computational study on the performance and emission parameters mapping of a ship propulsion system. 229(1), pp. 58-76.

Torbacke, M., Rudolphi, Å. K. \& Kassfeldt, E., 2014. Lubricants: Introduction to Properties and Performance. s.1.:John Wiley \& Sons Ltd.

Trivyza, N., Rentizelas, A. \& Theotokatos, G., 2018. A novel multi-objective decision support method for ship energy systems synthesis to enhance sustainability. Energy Conversion \& Management, Issue 168, pp. 128-149.

UNTAD, 2017. Review of Maritime Transport, New York: United Nations Conference on Trade and Development, October 2017, UNCTAD/RMT/2017.

Wang, K., Yan, X., Yuan, Y. \& Li, F., 2016. Real-time optimization of ship energy efficiency based on the prediction technology of working condition. Transportation Research Part D: Transport and Environment, Volume 46, pp. 81-93.

WinGD, 2018. General Technical Data-GTD2.3.1.0. [Online]

Available at: https://www.wingd.com/en/media/general-technical-data/

[Accessed 30 March 2018].

Wood, H. K. \& Stapersma, D., 2002. Design of Propulsion and Electric Power Generation Systems. s.l.:IMarEST.

Woodyard, D., 2003. Pounder's Marine Diesel Engines and Gas Turbines. 8th ed. s.1.:Butterworth-Heinemann. 